\title{
MicroGrids Operation and Control under Emergency Conditions
}

\author{
C. L. Moreira, J. A. Peças Lopes \\ INESC Porto - Instituto de Engenharia de Sistemas e Computadores do Porto \\ Campus da FEUP \\ Rua Dr. Roberto Frias, 378 \\ 4200-465 Porto \\ Portugal \\ carlos.moreira@inescporto.pt;.jpl@fe.up.pt
}

MicroGrids comprise low voltage distribution systems with distributed energy sources, storage devices and controllable loads, operated connected to the main power network or autonomously, in a controlled coordinated way. In case of MicroGrids autonomous operation, management of instantaneous active power balance imposes unique challenges. Traditionally, power grids are supplied by sources having rotating masses and these are regarded as essential for the inherent stability of the system. In contrast, MicroGrids are dominated by inverter interfaced sources that are inertia-less, but do offer the possibility of a more flexible operation. When a forced or scheduled islanding takes place in a MicroGrid, it must have the ability to operate stably and autonomously, requiring the use of suitable control strategies. The MicroGrid power sources can also be exploited in order to locally promote a service restoration strategy following a general blackout. A sequence of actions for the black start procedure is also presented and it is expected to be an advantage in terms of reliability as a result from the presence of very large amounts of dispersed generation in distribution grids.

\subsection{Introduction}

Recent technological developments are contributing to the maturity of some Distributed Generation (DG) technologies suitable to be connected to Low Voltage (LV) distribution grids. The interconnection of small modular generation systems (such as photovoltaic panels, fuel cells, microturbines or small wind generators) and energy storage devices to LV distribution grids will lead to the development of a new electrical LV grid usually referred as the MicroGrid (MG). 
These type of generation units - the MicroSources (MS) - are small units of less than $100 \mathrm{~kW}$ (electric power), most of them with power electronic interfaces, using either renewable energy sources or fossil fuels within a high efficiency local co-generation mode. A MG can thus be an extremely flexible cell of the electrical power system, being able to be operated interconnected to the main power system or autonomously in case of emergency situations if endowed with proper control and management systems [1-5]. A typical MG architecture is presented in Fig. 1. Regarding MG operation, two distinct operation modes can be defined [1]:

- Normal Interconnected Mode: the MG is connected to the upstream MV network, either being totally or partially supplied by it (depending on the dispatching procedures used to operate the MS) or injecting some amount of power into the main system (in case the relation between the MS production level and the total MG consumption allows this type of operation).

- Emergency Mode: following a failure in the upstream MV network, or due to some planned actions (for example, in order to perform maintenance actions) the MG can have the ability to smoothly move to islanded operation or to locally exploit a service restoration procedure in the advent of a general blackout. In both cases, the MG operates autonomously, in a similar way to the electric power systems of the physical islands.

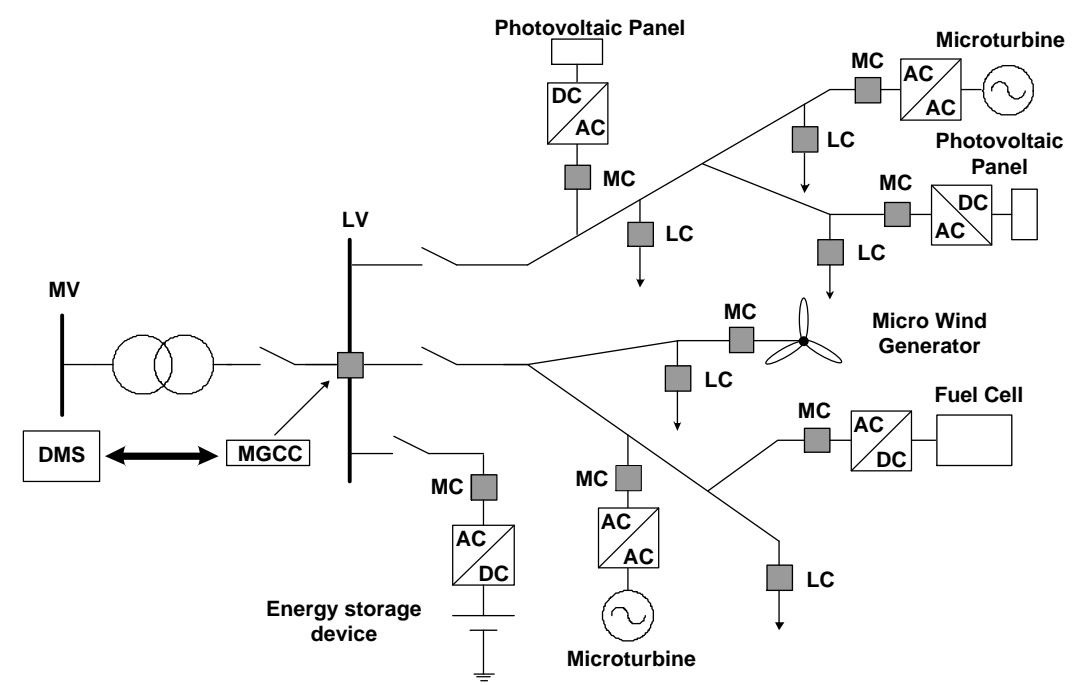

Fig. 1. MG architecture, comprising MS, energy storage devices and a hierarchical control and management system 


\subsubsection{An overview of MG operation}

In order to achieve the desired flexibility, the MG system in centrally controlled and managed by a device, named as MicroGrid Central Controller (MGCC), installed in the LV side of the MV/LV distribution transformer (as depicted in Fig. 1), which communicates with controllers located in a second hierarchical level. The second hierarchical control level comprises MS and storage devices being locally controlled by a Microsource Controller (MC) and the electrical loads or group of loads being controlled by a Load Controller (LC) [1, 6]. The proper operation and control of the entire system requires communication and interaction between the referred hierarchical control levels as follows:

- the LC and MC, on one hand, as interfaces to control loads (load curtailment in emergency situations and application of demand side management policies), and control MS active and reactive power production levels;

- the MGCC, on the other hand, as the central controller responsible for an adequate technical and economic management of the MG according to pre-defined criteria, by providing set-points to MC and LC.

It is also expected the MGCC to be able to communicate with the Distribution Management System (DMS), located upstream in the distribution network, contributing to improve the management and operation of the MV distribution system through contractual agreements that can be established between the MG and the Distribution Network Operator. In order to enable this scenario, the conventional approaches to DMS need to be enhanced with new features related to MG connected on the feeders. The issues of autonomous and non-autonomous operation of the MG and the related exchange of information are examples of new important issues to be tackled in the near future.

The MC can be housed within the power electronic interface of the MS. It is supposed to respond in milliseconds, using local information and the requests issued by the MGCC to control the MS. The MC will have autonomy to perform local optimization of the MS active and reactive power production, when connected to the power grid, and fast load-tracking following an islanding situation. LC also need to be installed at the controllable loads to provide load control capabilities following demands from the MGCC, under a Demand Side Management policy, or in order to implement load shedding functionalities during emergency situations. By exploiting the architecture presented in Fig. 1, the required operation and control functionalities that assure a stable operation in the first moments subsequent to transients are implemented based only on information available locally at the MC and LC terminals. Operational strategies intended for global MG optimization will run periodically (few minutes) in the MGCC and the resulting dispatch (voltage set-points, active and reactive power set-points, loads to be shed or deferred in time, etc.) will be communicated to local controllers (MC and LC) in a second stage corresponding to a larger time frame. 
The MGCC heads the technical and economic management of the MG. During the Normal Interconnected Mode, the MGCC collects information from the MC and $\mathrm{LC}$ in order to perform a number of functionalities. A key functionality to be installed in the MGCC is forecasting of local loads and generation. The MGCC will be responsible for providing system load forecasts (electric and possibly heat). It will also forecast in a simpler manner power production capabilities (exploiting information coming from wind speed, solar insulation levels, etc.) and it will use electricity and gas costs information and grid needs, together with security concerns and Demand Side Management requests, to determine the amount of power that the MG should absorb from the distribution system, optimizing the local production capabilities. The defined optimized operating scenario is achieved by controlling the MS and controllable loads in the MG in terms of sending control signals to the field [6].

In the Emergency Mode, an immediate change in the output power control of the MS is required, as they change from a dispatched power mode to one controlling frequency and voltage of the islanded section of the network. Under this operating scenario, the MGCC performs an equivalent action to the secondary control loops existing in the conventional power systems: after the initial reaction of the MC and LC, which should ensure MG survival following islanding, the MGCC performs the technical and economical optimization of the islanded system. It is also important to the MGCC to have accurate knowledge of the type of loads in the $\mathrm{MG}$ in order to adopt the most convenient interruption strategies under emergency conditions. Being an autonomous entity, the MG can also perform local Black Start (BS) functions under certain conditions. If a system disturbance provokes a general blackout such that the MG was not able to separate and continue in islanding mode, and if the MV system is unable to restore operation in a specified time, a first step in system recovery will be a local BS. The strategy to be followed will involve the MGCC, the MC and the LC using predefined rules to be embedded in the MGCC software. Such operational functionalities ensure an import advantage of the MG in terms of improved reliability and continuity of service [2].

\subsection{MicroGrids Dynamic Modelling}

The development of the MG concept previously described is based on a hierarchical distributed control architecture, where during some emergency situations an autonomous control should be able to run the system. Conceptually speaking, three operating conditions can be distinguished:

- Grid-connected mode;

- Islanding mode;

- Local Black Start. 
In order to analyse the referred operating conditions, it is necessary to address particular issues related to MS modelling and control. The models need to describe the dynamic behaviour of MS and their corresponding power electronic interfaces. This is an important requirement, since most of the MS technologies that can be installed in a MG are not suitable for direct connection to the electrical network due to the characteristics of the energy they produce. Therefore, power electronic interfaces (DC/AC or $\mathrm{AC} / \mathrm{DC} / \mathrm{AC})$ are required and need to be adequately modelled. Aiming to consider the full modelling of each MS and the corresponding power electronic interface, Fig. 2 shows the basic configuration of these types of systems. The blocks represented in the figure are:

- The MS (fuel cell, microturbine, etc);

- A DC-link (DC capacitor C), which connects the MS to the DC-AC inverter (grid-side inverter);

- A low-pass LC filter, which rejects the inverter generated high frequency harmonics;

- A coupling inductance.

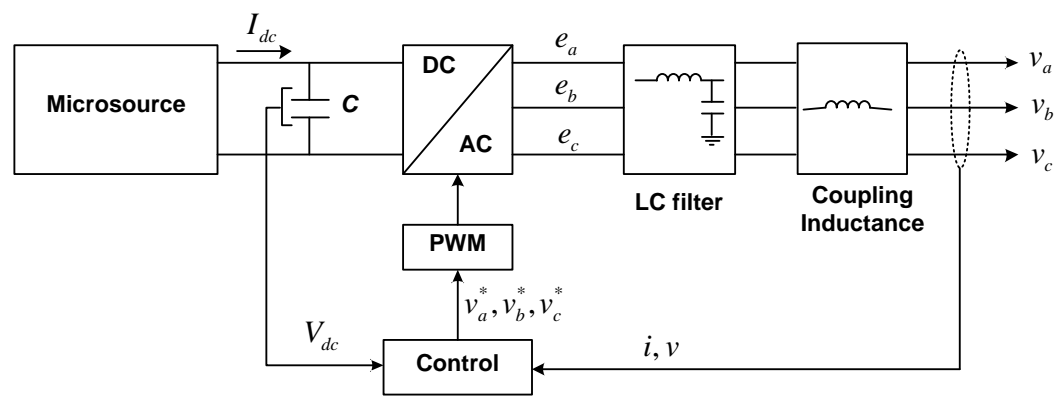

Fig. 2. Block diagram of an inverter interfaced MS

In the following sub-sections it is presented a brief overview of the dynamic models that are required in order to perform the analysis of different MS types. These models describe MS and storage devices response and they will be used in order to evaluate MG operation during islanding conditions. Later, the dynamic models for the power electronic interfaces used to connect the MS to the LV grids will be also discussed.

\subsubsection{Fuel cells}

Fuel cells are electrochemical devices that convert the chemical energy contained in a wide variety of fuels directly into electric energy. The basic element of a fuel cell is a unit cell, as shown in Fig. 3. [7, 8]. Each basic fuel cell unit consists of a cathode (positively charged electrode), an anode (negatively charged electrode) and an electrolyte layer. The anode provides an interface between the fuel 
and the electrolyte, catalyses the fuel reaction, and provides a path through which free electrons are conduct to the load via the external circuit. The overall fuel cell reactions occur in two steps: the oxidation reaction at the anode and the reduction reaction at the cathode. The oxidation reaction is the dissociation of hydrogen atoms into protons and electrons. The reduction reaction occurs when the oxygen atoms dissociate and bond with the protons coming through the membrane and the electrons from the external circuit, forming water.

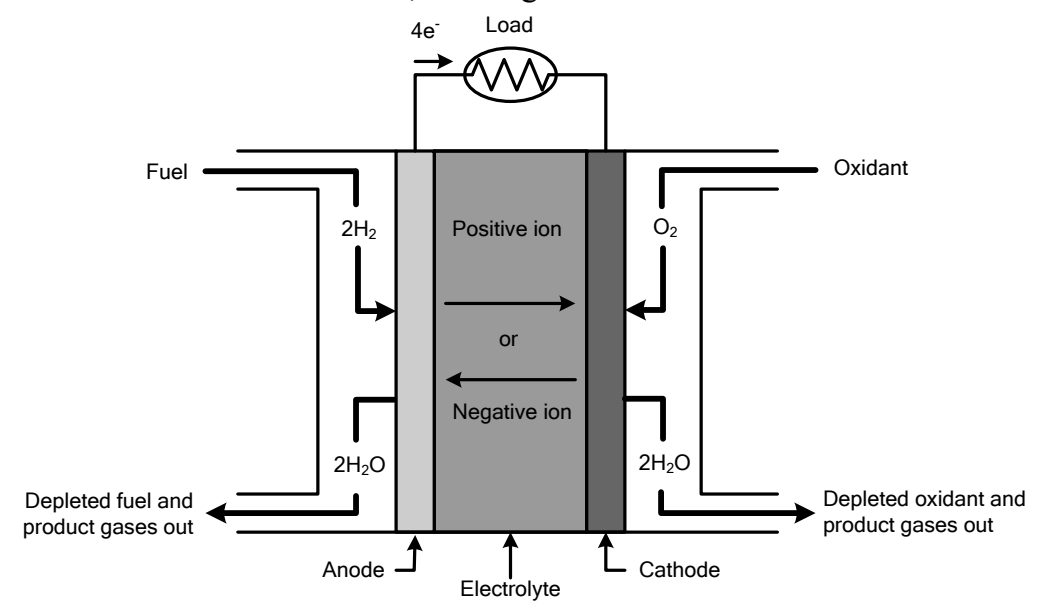

Fig. 3. Schematic diagram of a basic fuel cell unit

There are five basic types of fuel cells, each having different electrolytes which define the basic cell type, and a characteristic operating temperature [7-9]. Two of these fuel cell types, Polymer Electrolyte Membrane Fuel Cell (PEMFC) and Phosphoric Acid Fuel Cell (PAFC) have acidic electrolytes and rely on the transport of $\mathrm{H}^{+}$ions. Therefore, they are classified as proton-conducting fuel cells. Direct Methanol Fuel Cells (DMFC) make also part of this group, since it is basically a PEMFC in which methanol or another alcohol is directly used. Two others types, Alkaline Fuel Cell (AFC) and Molten Carbonate Fuel Cell (MCFC) have basic electrolytes that rely on the transport of $\mathrm{OH}^{-}$and $\mathrm{CO}_{3}{ }^{2-}$ ions, respectively. The fifth type, Solid Oxide Fuel Cell (SOFC) is based on a solid-state ceramic electrolyte in which oxygen ions $\left(\mathrm{O}^{2-}\right)$ are the conductive transport ion. The later three types are classified as anion conducting fuel cells. Additional information on each type of fuel cell can be found in [7].

\subsubsection{Solid oxide fuel cell modelling}

A SOFC was chosen to be included in the MG system, since it is particular interesting for stationary power generation due to its high temperature operation characteristics, making it suitable for combined heat and power applications. Nev- 
ertheless, being a high temperature fuel cell, the SOFC system present some major drawbacks. Due to the high-temperature operation, it requires a significant time to reach the operating temperature ant to respond to changes in the output power. Also, its start-up time is in the order of 30 to 50 minutes. Packing of the entire system (fuel cell stack, power electronic equipment, etc.) is also quite demanding due to the different range of temperatures of the different components[10].

The SOFC model described in this section is based in the works reported in [11-15] and is it based on the following assumptions:

- The gases are ideal;

- The stack is fed with hydrogen and air;

- The channels that transport gases along the electrodes have a fixed volume, but their lengths are small. Thus, it is possible to consider one single pressure value in their interior;

- The exhaust of each channel is via a single orifice. The ratio of pressures between the interior and exterior of the channel is large enough to consider that the orifice is choked;

- The temperature is stable at all times;

- The only source of losses is ohmic, as the working conditions of interest are not close to the upper and lower extremes of the cell current;

- The Nernst equation can be applied.

Assuming that the SOFC system is supplied with hydrogen in the anode and oxygen in the cathode, the reactions that take place are described by the following chemical equations [11-15]:

$$
\begin{array}{ll}
\text { Anode: } & \mathrm{H}_{2}+\mathrm{O}^{=} \rightarrow \mathrm{H}_{2} \mathrm{O}+2 \mathrm{e}^{-} \\
\text {Cathode: } & \frac{1}{2} \mathrm{O}_{2}+2 \mathrm{e}^{-} \rightarrow \mathrm{O}^{=}
\end{array}
$$

In order to calculate the open circuit voltage $E$ (in $\mathrm{V}$ ) of a stack with $N_{0}$ cells connected in series, the Nernst equation is used:

$$
E=N_{0}\left[E_{0}+\frac{R T}{2 F} \ln \frac{p_{\mathrm{H}_{2}} \sqrt{p_{\mathrm{O}_{2}}}}{p_{\mathrm{H}_{2} \mathrm{O}}}\right]
$$

where $E_{0}$ is the voltage associated with reaction free energy of the cell $(\mathrm{V}), R$ is the universal gas constant $\left(8314.51 \mathrm{~J} \cdot \mathrm{kmol}^{-1} \cdot \mathrm{K}^{-1}\right), T$ is the channel temperature, assumed to be constant $(\mathrm{K}), F$ is the Faraday constant $\left(96.487 \times 106 \mathrm{C} . \mathrm{kmol}^{-1}\right)$ and $p_{\mathrm{H}_{2}}, p_{\mathrm{O}_{2}}, p_{\mathrm{H}_{2} \mathrm{O}}$ are the partial pressures of hydrogen, oxygen and water vapour, respectively (atm). Applying Ohm's law, the stack output voltage can be computed as: 


$$
V=E-r I
$$

where $r$ is the SOFC resistance used to represent the ohmic losses in the stack $(\Omega)$ and $I$ is the current flowing out of the stack (A).

In order to compute the stack voltage, the pressure of the gases inside the stack must be derived. The individual gases (hydrogen, oxygen and water vapour) flowing in the stack will be considered separately, and the perfect gas equation is applied to them:

$$
p_{i} V_{c h}=n_{i} R T
$$

where $p_{i}$ are the pressures of each chemical species in the cell (atm), $V_{c h}$ is the volume of the channel (anode or cathode), in litres, and $n_{i}$ is the number of moles of the specie $i$ present in the channel. As the cell temperature is assumed to be constant, by differentiating both sides of (3), it is possible to derive a relation between the time derivative of the partial pressures and the time derivative of $n_{i}$, which denotes the species molar flow $\left(\mathrm{kmol} . \mathrm{s}^{-1}\right)$ :

$$
\frac{d p_{i}}{d t}=\frac{R T}{V_{c h}} \frac{d n_{i}}{d t}=\frac{R T}{V_{c h}} q_{i}
$$

Regarding hydrogen, it flows through the stack anode with volume $V_{a n}$ and there are three contributions to its molar flow: the input flow $\left(q_{H_{2}}^{i n}\right)$, the output flow $\left(q_{H_{2}}^{\text {out }}\right)$ and the input flow that takes part in the stack reactions $\left(q_{H_{2}}^{r}\right)$. Thus, the hydrogen pressure can be obtained by the following equation:

$$
\frac{d p_{H_{2}}}{d t}=\frac{R T}{V_{a n}}\left(q_{H_{2}}^{\text {in }}-q_{H_{2}}^{o u t}-q_{H_{2}}^{r}\right)
$$

The hydrogen molar flow that reacts can be calculated as:

$$
q_{H_{2}}^{r}=\frac{N_{o} I}{2 F}=2 K_{r} I
$$

being $K_{r}$ a constant defined for modelling purposes $\left(\mathrm{kmol} . \mathrm{s}^{-1} \cdot \mathrm{A}^{-1}\right)$. The molar flow of any gas through a valve can be considered proportional to its partial pressure inside the channel. Therefore, the following equation stands:

$$
\frac{q}{p}=\frac{K_{c h}}{\sqrt{M}}=K
$$


where $K_{c h}$ is the channel valve constant $\left((\mathrm{kmol} . \mathrm{kg})^{1 / 2} \cdot \mathrm{atm}_{\mathrm{s}} \mathrm{s}^{-1}\right), M$ is the gas mo-

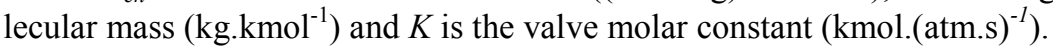

Using (7) to calculate the hydrogen output flow and substituting in (5), the differential equation for the hydrogen dynamics is obtained:

$$
\frac{d p_{H_{2}}}{d t}=\frac{R T}{V_{a n}}\left(q_{H_{2}}^{i n}-K_{H_{2}} p_{H_{2}}-2 K_{r} I\right)
$$

Taking the Laplace transform of both sides of (8) and isolating the hydrogen partial pressure, yields the following expression:

$$
p_{H_{2}}=\frac{1 / K_{H_{2}}}{1+\tau_{H_{2}} S}\left(q_{H_{2}}^{i n}-2 K_{r} I\right)
$$

being $\tau_{\mathrm{H}_{2}}=\frac{V_{a n}}{K_{\mathrm{H}_{2}} R T}$, expressed in seconds, the time constant associated with the hydrogen flow dynamics.

Considering this general procedure for deriving the equation describing hydrogen dynamics in the fuel cell, a similar procedure can be used for the other chemical species (oxygen and water vapour). According to the electrochemical relationships, the molar flow of oxygen that reacts is $q_{O_{2}}^{r}=K_{r} I$. Therefore, the dynamic behaviour related to the oxygen flow is described by:

$$
p_{O_{2}}=\frac{1 / K_{O_{2}}}{1+\tau_{O_{2}} s}\left(q_{O_{2}}^{i n}-K_{r} I\right)
$$

where $\tau_{O_{2}}=\frac{V_{c t}}{K_{O_{2}} R T}$, expressed in seconds, the time constant associated with the oxygen flow dynamics.

According to the chemical reactions taking place in the SOFC, water is a reaction product in the stack anode. Therefore, for the water vapour, (5) can be rewritten as:

$$
\frac{d p_{\mathrm{H}_{2} \mathrm{O}}}{d t}=\frac{R T}{V_{a n}}\left(q_{\mathrm{H}_{2} \mathrm{O}}^{r}-q_{\mathrm{H}_{2} \mathrm{O}}^{\text {out }}\right)
$$


The molar flow of water vapour resulting from the chemical reactions $\left(q_{\mathrm{H}_{2} \mathrm{O}}^{r}\right)$ is $q_{\mathrm{H}_{2} \mathrm{O}}^{r}=q_{\mathrm{H}_{2}}^{r}=2 K_{r} I$. The dynamics related to the water vapour flow can be described by:

$$
\frac{d p_{\mathrm{H}_{2} \mathrm{O}}}{d t}=\frac{R T}{V_{a n}}\left(q_{\mathrm{H}_{2} \mathrm{O}}^{r}-q_{\mathrm{H}_{2} \mathrm{O}}^{\text {out }}\right)
$$

being $\tau_{\mathrm{H}_{2} \mathrm{O}}=\frac{V_{a n}}{K_{\mathrm{H}_{2} \mathrm{O}} R T}$, expressed in seconds, the time constant associated with the water vapour flow.

The previous equations are related to the dynamics of the chemical species in the SOFC. However, due to safety reasons associated with the physical integrity of the cell under certain conditions, some considerations need to be made in relation to the electric current resulting from the chemical reactions. In order to do this, it is necessary to define the fuel utilization parameter $U_{f}$ : it is the ratio of the fuel flow that reacts in the stack and the input fuel flow,

$$
U_{f}=\frac{q_{H_{2}}^{\text {in }}-q_{H_{2}}^{\text {out }}}{q_{H_{2}}^{\text {in }}}=\frac{q_{H_{2}}^{r}}{q_{H_{2}}^{\text {in }}}=\frac{2 K_{r} I}{q_{H_{2}}^{\text {in }}}
$$

The typical value of the fuel utilization is in the range of $80 \%$ to $90 \%$. The underused condition $\left(U_{f}<80 \%\right)$ would lead to a fast voltage increase, since the current will be below a minimum value. The overused condition $\left(U_{f}>90 \%\right)$ will cause permanent damage to the cell due to fuel starvation. Therefore, for a certain hydrogen molar flow, the current demanded to the fuel cell must be restricted to the following range:

$$
\frac{0.8 q_{H_{2}}^{i n}}{2 K_{r}} \leq I \leq \frac{0.9 q_{H_{2}}^{i n}}{2 K_{r}}
$$

The optimal fuel utilization factor $\left(U_{\text {opt }}\right)$ is assumed to be $85 \%$, allowing the control of the input fuel flow by measuring the output current, so that:

$$
q_{H_{2}}^{i n}=\frac{2 K_{r} I}{U_{o p t}}
$$

According to the chemical reactions taking place in the fuel cell, the stoichiometric ratio of hydrogen to oxygen is $2: 1$. However, oxygen is always taken in excess in order to allow a more complete reaction between hydrogen and 
oxygen. In order to keep fuel cell pressure difference between the hydrogen and oxygen passing through the anode and cathode compartments bellow $4 \mathrm{kPa}$ under normal operating conditions, the ratio of hydrogen to oxygen is controlled by an air compressor to be $\mathrm{r}_{\mathrm{H}-\mathrm{O}}=1.145$.

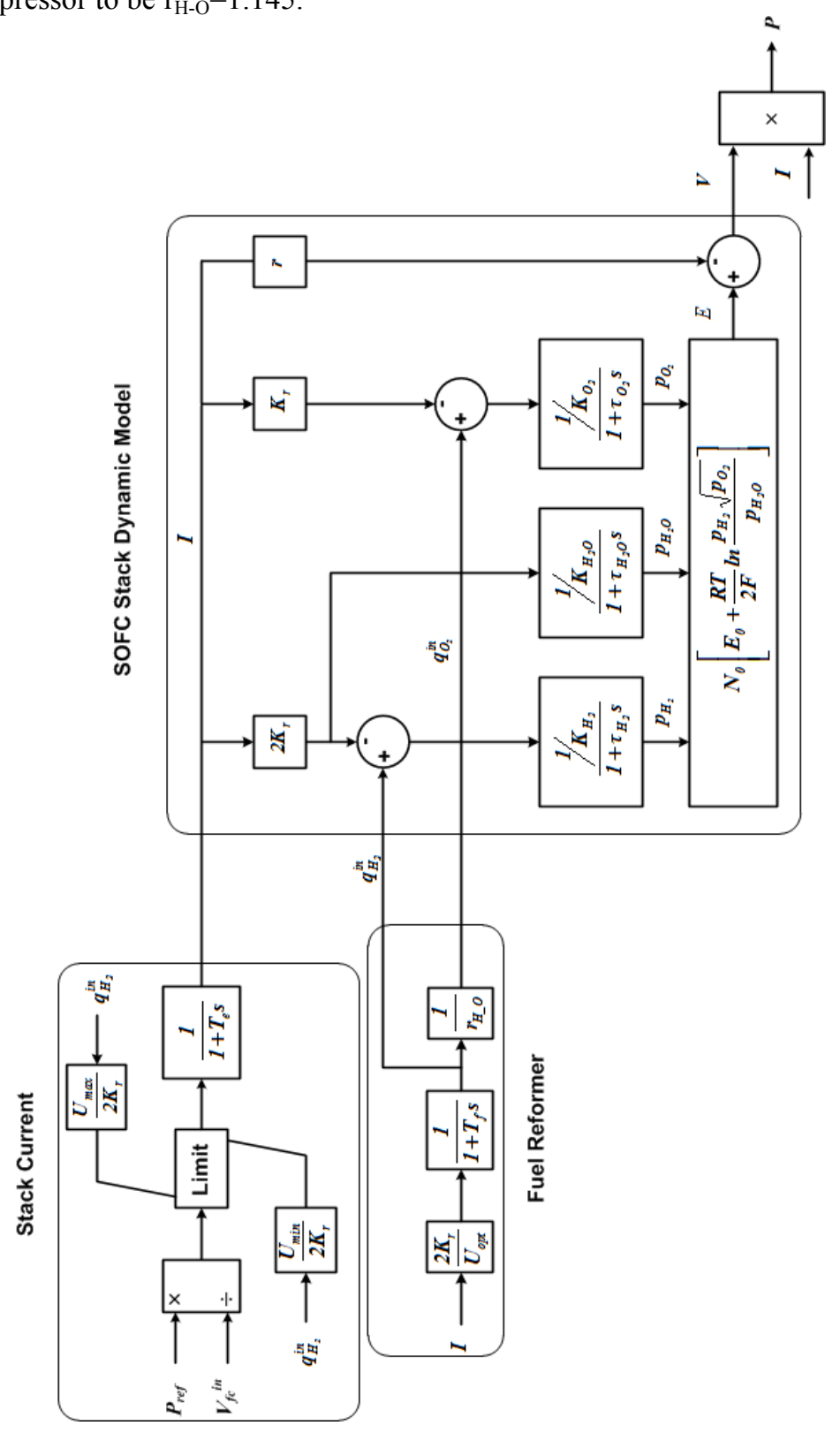

Fig. 4. SOFC dynamic model 
All the reactions occurring in the fuel cell stack has some inherent time delays. The chemical response in the fuel cell processor is usually slow and it is associated with the time to change the chemical reaction parameters after a change in the flow of reactants. This dynamic response function is modelled as a first order transfer function with a time delay $T_{f}$. The electrical response time delay in the fuel cells is generally short and mainly associated with the speed at which the chemical reaction is capable of restoring the charge that has been drained by the load. This dynamic response is also modelled as a first order transfer function, with a time delay $T_{e}$. Following the previous explanations, Fig. 4 shows the block diagram of the SOFC dynamic model.

\subsubsection{Microturbines}

Microturbines are small gas turbines with electrical power output of approximately $30 \mathrm{~kW}$ to $400 \mathrm{~kW}$, burning gaseous or liquid fuels [11, 16-20]. Single Shaft Microturbines (SSMT) is the most common configuration: it consists on the compressor, the expansion turbine and the electrical generator sharing a common shaft rotating at very high speeds, as depicted in Fig. 5. The typical SSMT rotation speeds is variable (in the range of $50000 \mathrm{rpm}$ to $120000 \mathrm{rpm}$ ) in order to accommodate varying load profiles, while maintaining high efficiencies and optimum long term reliability [16]. The electrical generator is usually a variable speed Permanent Magnet Synchronous Generator (PMSG) that produces high-frequency $\mathrm{AC}$ power, being converter to line frequency AC power through a power electronic stage. When the SSMT is started-up, the electrical generator acts as a motor, turning the turbine-compressor shaft until sufficient speed is achieved to start and sustain the combustion process. If the system is operated independently from the electrical grid, energy storage units such as batteries are required to power the generator during the start-up process, which provides an interesting functionality regarding its application in a BS procedure.

Microturbines are recognized to play an increasing importance for small scale power generation applications, but little work on its modelling and simulation is reported in the literature. More specifically, modelling of microturbine dynamic behaviour has a major interest in terms of the slow dynamics, namely its response to load changes and the ability to perform frequency regulation. Therefore, based on the models reported in $[11,16,17,20]$ some assumptions are due in order to derive a model able to conveniently represent microturbine dynamics. As a first consideration, the SSMT engine, while small in size, is assumed to be similar to conventional combustion gas turbines. Additionally, evaluating the integration of microturbines in an electric network from a dynamic point of view requires a model able to represent the electric and mechanic behaviour. The use of hot exhaust gases in the recuperator is not considered in the adopted model since this is only a device used to increase microturbine global efficiency. Also, the large time constants associated to the recuperator has little influence regarding the time scale 
used for dynamic simulations. It is also frequent to find temperature, speed and acceleration control systems in microturbines. These kinds of control systems are very important during start-up or loss of power conditions, but have very little influence during normal operating conditions. Thus, they can be neglected when the main interest is focused on the evaluation of microturbine slow dynamics. Based on these assumptions, the model should reflect the dynamics of the blocs represented in Fig. 6: microturbine control and mechanical system, electrical generator and the power electronic interface to connect the microturbine to the electric power grid.

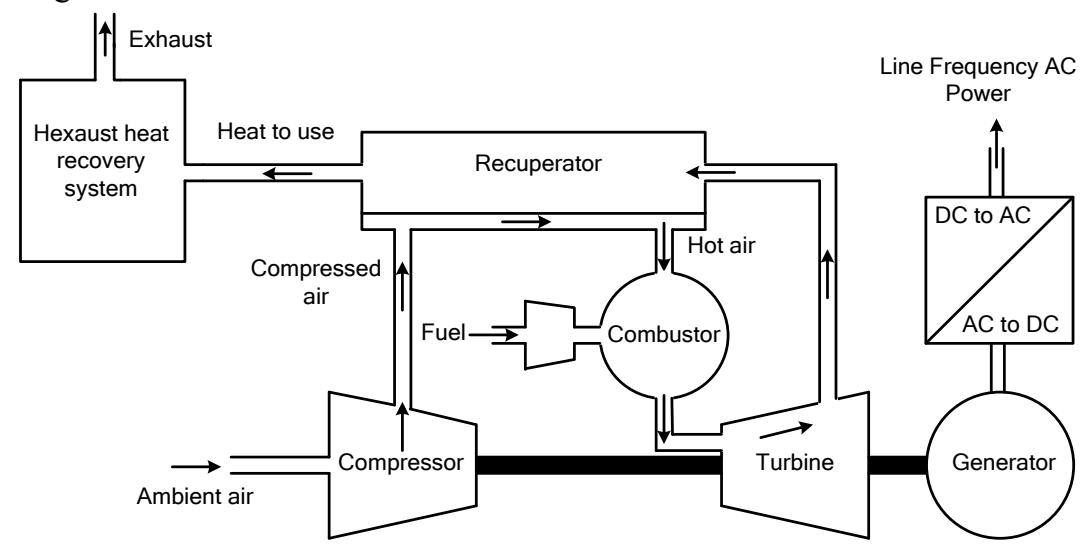

Fig. 5. Single shaft microturbine system

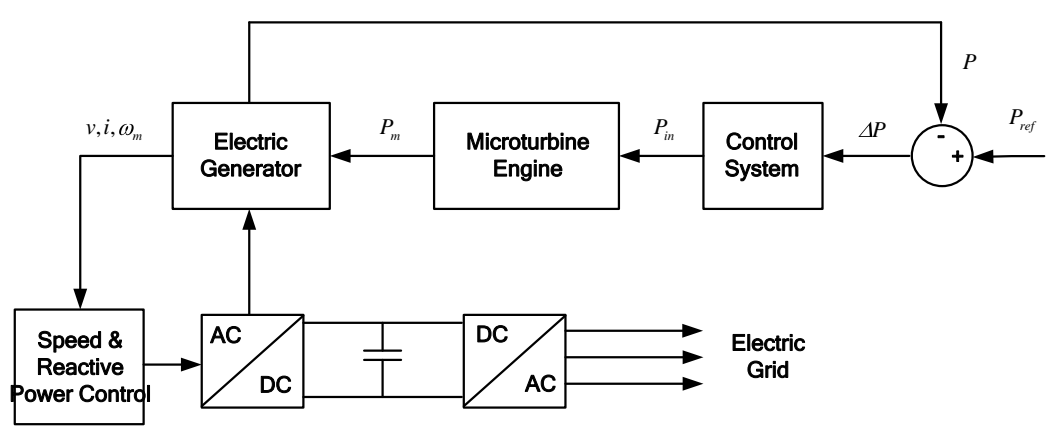

Fig. 6. Block diagram of the SSMT control system

\subsubsection{SSMT active power control}

In order to control the power output of the SSMT, a power set-point should be provided to the control system. A simple control of the turbine mechanical power can be performed through a Proportional-Integral (PI) control function [11]. The input of the controller is the error $\Delta P$ between the power set-point $P_{\text {ref }}$ and the ef- 
fective power output $P$. The output of the controller $P_{i n}$ is then applied to the microturbine engine, as shown in Fig. 7.

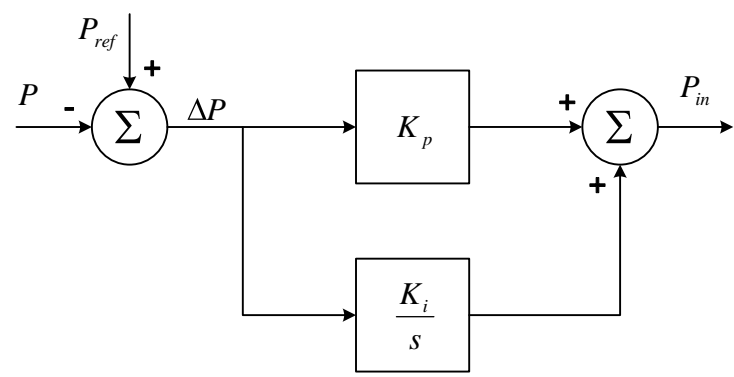

Fig. 7. SSMT active power control

\subsubsection{SSMT engine}

The SSMT engine comprises an air compressor, a combustion chamber, a recuperator and a power turbine driving the electrical generator. This arrangement is quite similar to combustion gas turbines [17]. Therefore, the mechanical part of the SSMT (SSMT engine) can be modelled by the conventional model commonly use to represent the dynamics of simple cycle single shaft gas turbines, usually known as the GAST (GAS Turbine) model, without the droop control, as in Fig. 8 [11]. The parameters in the microturbine engine model are $T_{1}$ and $T_{2}$, representing the fuel system time constant, $T_{3}$ is the load limit time constant, $V_{\max }$ and $V_{\min }$ are the maximum and minimum fuel valve positions, $k_{t}$ is the temperature control loop gain and $L_{\max }$ is the load limit (time constants in seconds and the other parameters are in per unit).

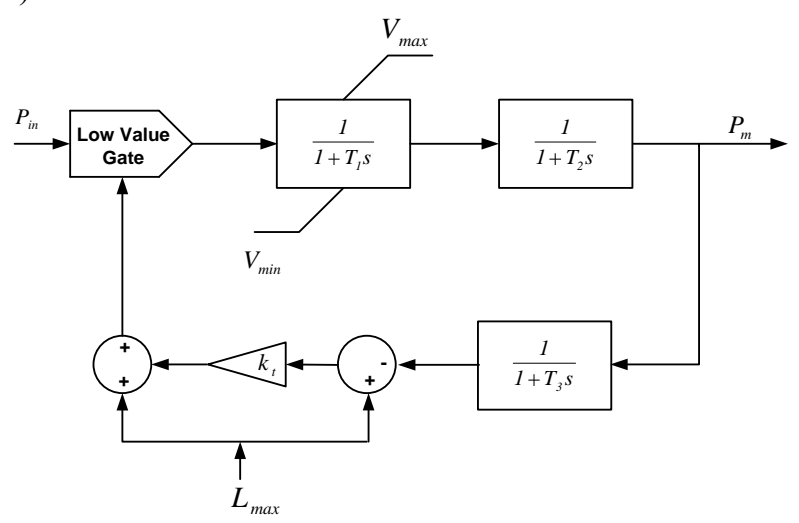

Fig. 8. Dynamic model of the SSMT engine 


\subsubsection{Permanent magnet synchronous generator}

The electrical generator is assumed to be a PMSG with a non-salient rotor. The machine electrical equations can be written in the rotor $d-q$ reference in frame as follows [19]:

$$
\begin{aligned}
& v_{d}=R_{s} i_{d}-p \omega L_{q} i_{q}+L_{d} \frac{d i_{d}}{d t} \\
& v_{q}=R_{s} i_{q}+p \omega L_{d} i_{d}+L_{q} \frac{d i_{q}}{d t}+p \omega \Phi_{m} \\
& T_{e}=\frac{3}{2} p\left[\Phi_{m} i_{q}+\left(L_{d}-L_{q}\right) i_{d} i_{q}\right]
\end{aligned}
$$

where $L_{d}$ and $L_{q}$ are the $d$ and $q$ axis inductances $(\mathrm{H}), R_{s}$ is the stator resistance $(\Omega), i_{d}$ and $i_{q}$ are the $d$ and $q$ axis currents (A), $v_{d}$ and $v_{q}$ are the $d$ and $q$ axis terminal voltages $(\mathrm{V}), \quad$ is the angular velocity of the rotor $\left(\operatorname{rad} . \mathrm{s}^{-1}\right), \Phi_{m}$ is the flux inducted by the permanent magnets $(\mathrm{Wb}), p$ is the number of pole pairs and $T_{e}$ is the electromagnetic torque (N.m). The mechanical equation needs to take into account the combined inertia and load viscous friction of the PMSG, the power turbine and compressor that are mounted in the same shaft:

$$
T_{e}-T_{m}=J \frac{d \omega}{d t}+F \omega
$$

where $T_{m}$ is the mechanical torque provided to the PMSG by the SSMT engine, $J$ is the combined inertia of the PMSG, shaft, turbine and compressor $\left(\mathrm{kg} . \mathrm{m}^{2}\right)$ and $F$ is the combined friction factor in the same components (N.m.s.rad $\left.{ }^{-1}\right)$.

\subsubsection{PMSG side converter}

The variable frequency AC power produced in the PMSG must be rectified and inverted in order to be injected into the AC grid. The machine side converter is responsible for controlling the PMSG operation in terms of rotation speed and power factor [21]. A block diagram of the machine side converter and its control structure is shown in Fig. 9. The microturbine shaft speed is controlled through a pre-defined characteristic curve ( versus $P$ ) in order to operate the microturbine at optimal efficiency for each value of the output power [19]. The microturbine speed error is used to compute the $i_{d}$ reference current, which is supplied to a PI controller in order to regulate the direct axis voltage $v_{d}$ and thus the microturbine angular velocity. The quadrature axis voltage $v_{q}$ can be regulated in order to assure a unit power factor for the PMSG. 


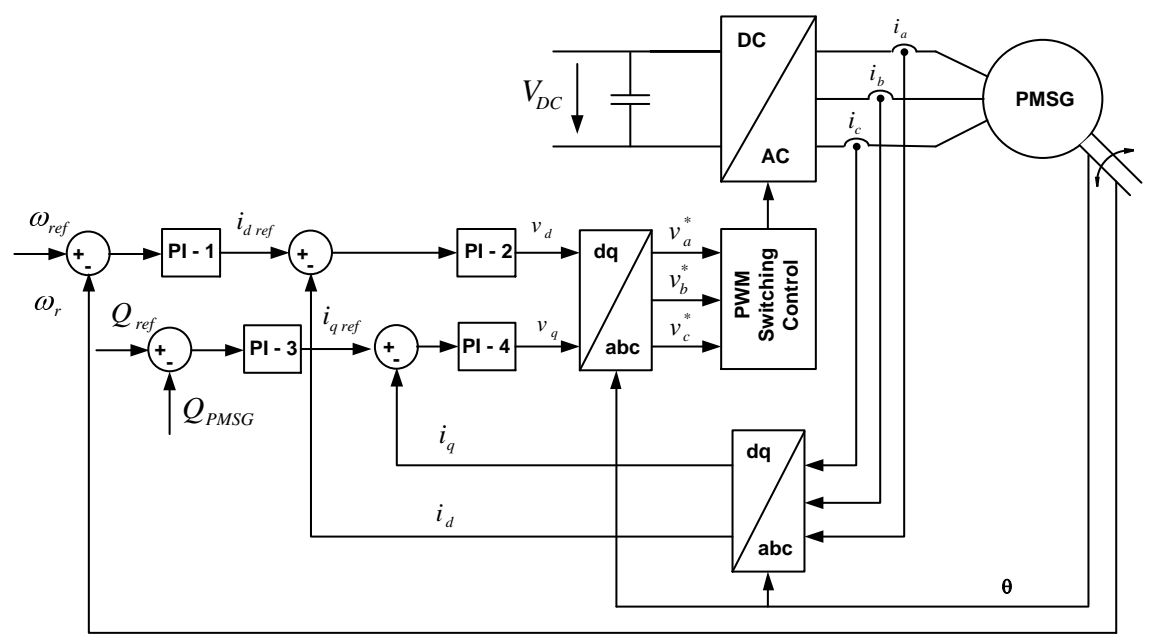

Fig. 9. Block diagram of the PMSG side converter control

\subsubsection{Micro-wind turbines}

The horizontal wind turbines is the one of the most commonly used configurations in small scale applications. It generally consists of a rotor where the turbine is solidly fixed, an electrical generator, a mainframe and a tail. The turbine usually consists of two or three blades. The electrical generator is specifically designed for the wind turbine. PMSG are the most used generators for this kind of application since they do not require brushes as in direct current machines and in some conventional synchronous generators with separate excitation systems. In most small and micro- wind turbine designs, the rotor is connected directly to the shaft of the PMSG, thus creating variable frequency and voltage AC power, according to the wind speed. The output power is then rectified to DC to either charge batteries or feed a grid-synchronous inverter. In the designs with a direct coupling between the turbine and the generator, high reliability and lower cost is achieved since the design eliminates the additional maintenance of gears and the relatively low reliability indexes of these devices [6].

According to these general considerations, modelling of micro-wind generators follows the same approach used when presenting the description SSMT modelling, especially in that concerns the PMSG and the PMSG side converter. The mechanical power extracted by the wind turbine from the wind kinetic energy, is given by [22]:

$$
P_{m}=\frac{1}{2} \rho \times C_{p} \lambda \times A \times V^{3}
$$


where $P_{m}$ is the turbine mechanical power $(\mathrm{W}), C_{p}(\lambda)$ is a dimensionless performance coefficient of the turbine, $\lambda$ is the tip speed ratio ( $\mathrm{rad}), \rho$ is the air density $\left(\mathrm{kg} . \mathrm{m}^{-3}\right), A$ is the area swept by the rotor $\left(\mathrm{m}^{2}\right)$ and $V$ is the wind speed $\left(\mathrm{m} . \mathrm{s}^{-1}\right)$.

Independently from the type of wind turbine, its efficiency can be calculated by the quotient between the mechanical power $P_{m}$ delivered by the turbine and the power effectively available due to the wind flow. This coefficient is usually defined as $C_{p}(\lambda)$. The parameter $\lambda$ is defined as:

$$
\lambda=\frac{\omega_{t} R}{V}
$$

where ${ }_{t}$ is the angular velocity of the turbine $\left(\mathrm{rad}_{\mathrm{s}} \mathrm{s}^{-1}\right)$ and $R$ is the turbine radius (m).

Regarding micro-wind turbine operation, it is controlled in order to extract the maximum amount of power from the available wind through the use of a maximum power extraction curve that can be derived from the turbine characteristics. This curve is used in the PSMG side converter in order to control its rotational speed, as in the SSMT case.

\subsubsection{Photovoltaic panels}

There are several models reported in the literature with different complexity levels that can be used to describe the behaviour of a Photovoltaic (PV) cell. The most widely used models are the ones based on lumped circuits, such as single and double diode models [23]. Within this class of mathematical models, the single diode model is one of the most widely used for representing PV systems.

Due to the particular voltage-current characteristic of the PV cells, it is necessary to use control schemes for extracting the maximum energy of the panel. Therefore, a PV system contains a module responsible for achieving an operation point corresponding to the condition of maximum energy extraction. This module is denominated as Maximum Power Point Tracker (MPPT), and it is represented in Fig. 10. Basically, the PV system consists in the PV array, which is connected to the MPPT (a DC/DC converter controlled through proper algorithms) and the $\mathrm{DC} / \mathrm{AC}$ converter for connecting the PV system to the grid.

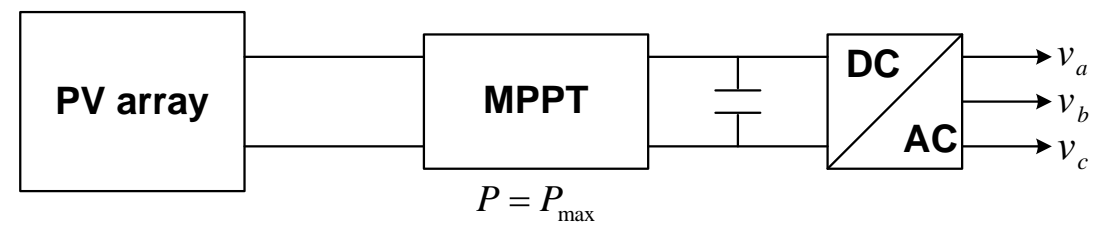

Fig. 10. Basic configuration of a PV system 
Several MPPT algorithms have been reported in the literature [24], differing among them in many aspects such as the complexity of the algorithm, required sensors, convergence speed and requirement of periodic tuning of the controllers. Within the scope of this chapter, the performance of the MPPT algorithm is not a key issue since MG dynamic studies are usually performed over a short period of time during which the solar radiation can be considered constant. Therefore, a simpler algorithm based on the following assumptions can be used [25]:

- All the cells of the PV module are identical and they work with the same irradiance level and at the same temperature;

- The PV module and the MPPT system has no losses;

- The PV module is always working on its maximum power point for a given irradiance and ambient temperature conditions;

- If the irradiance and/or ambient temperature conditions change, the model instantaneously changes its maximum power point;

- The temperature of the solar cells depends exclusively on the irradiance and ambient temperature.

Under these assumptions the module maximum output power $\mathrm{P}_{\mathrm{Max}}{ }^{\mathrm{M}}$ (in $\mathrm{W}$ ) can be estimated using the ambient temperature and the solar irradiance as inputs [25]:

$$
P_{M a x}^{M}=\frac{G_{a}}{G_{a, 0}}\left[P_{M a x, 0}^{M}+\mu_{P_{M a x}} T_{M}-T_{M, 0}\right]
$$

where $G_{a}$ is the solar irradiance $\left(\mathrm{W} . \mathrm{m}^{-2}\right), G_{a, 0}$ is the solar irradiance at Standard Test Conditions (1000 W.m $\left.{ }^{-2}\right), P_{M a x, 0}{ }^{M}$ is the PV module maximum power at Standard Test Conditions (W), $\mu_{P \max }$ is the maximum power variation with the temperature $\left(\mathrm{W} .{ }^{\circ} \mathrm{C}^{-1}\right), T_{m}$ is the module temperature $\left({ }^{\circ} \mathrm{C}\right)$ and $T_{M, 0}$ is the module temperature at Standard Test Conditions $\left(25^{\circ} \mathrm{C}\right)$. In practice, the operating conditions of PV systems differ from the Standard Test Conditions. Then, under arbitrary operating conditions (irradiance $G_{a}$ and ambient temperature $T_{a}$ ), the working temperature of the PV module $T_{M}$ is given by:

$$
T_{M}=T_{a}+G_{a} \frac{N O C T-20}{800}
$$

where NOTC is the Normal Operating Temperature of the Cell, which is defined as the cell temperature under a solar irradiance of $800 \mathrm{~W} \cdot \mathrm{m}^{-2}$, an ambient temperature of $20^{\circ} \mathrm{C}$ and a wind speed lower than $1 \mathrm{~m} . \mathrm{s}^{-1}$. These conditions are usually referred as the Normal Test Conditions. The maximum power of a PV array with $N$ modules is therefore given by: 


$$
P_{\text {Max }}=N \frac{G_{a}}{1000}\left[P_{\operatorname{Max}, 0}^{M}+\mu_{P_{\operatorname{Max}}}\left(T_{a}+G_{a} \frac{N O C T-20}{800}-25\right)\right]
$$

\subsubsection{Power electronic interfaces connected to the grid}

The characteristics of the energy produced in several MS require the use of power conditioning units in order to interface them with the LV grid. It is also important to note that MG are inverted dominated grids. It will not be common to find fully controllable synchronous generators in a MG, which are normally responsible for voltage and frequency control in conventional power systems. Therefore, understanding inverter controls is a key issue to ensure stable MG operation in the presence of arbitrary varying conditions (load or generation variations). In a MG, the massive integration of power electronic converters poses distinguishing characteristics in comparison to conventional power systems. Table 1 illustrates the key differences between synchronous machines and power electronic interfaces [26].

The inverter control strategies for power export to an AC system can be generally divided in two types [27]:

- $P Q$ inverter control: the inverter is used to supply a given active and reactive power set-point. In this case, the inverter operates in a grid-connected mode $[26,28]$, being the power injected into an energized network. The inverter is not able to form the grid itself by imposing a voltage waveform with suitable amplitude and frequency.

- Voltage Source Inverter control: the inverter is controlled to supply the load with pre-defined values for voltage and frequency. Depending on the load, the Voltage Source Inverter (VSI) real and reactive power output is defined. In this case, the inverter is responsible to establish the voltage wave form with suitable amplitude and frequency [26, 28]. The inverters themselves produce an AC voltage; therefore it is possible to control voltage and frequency in the AC system by means of inverter control.

Due to the fast response of power electronic converters, they can be modelled from the network point of view by a controllable AC voltage source. The magnitude and the phase angle of this voltage source are to be controlled according to the referred inverter control strategies. It is also important to highlight that, when analysing the dynamic behaviour of the MG, inverters are modelled based only on their control functions, so that, fast switching transients, harmonics and inverter losses are neglected. This a general procedure adopted by several authors when dealing with power electronic interfaces in dynamic stability studies [1-4, 29, 30]. 
Table 1. Comparison between synchronous machines and inverters general characteristics

\begin{tabular}{|c|c|}
\hline Synchronous Machines & Power Electronic Interfaces \\
\hline $\begin{array}{l}\text { Voltage source operation with controlled mag- } \\
\text { nitude through the use of excitation systems. }\end{array}$ & $\begin{array}{l}\text { Voltage source (although current source ver- } \\
\text { sions are known) with nearly independent con- } \\
\text { trol of the magnitude in each phase. }\end{array}$ \\
\hline $\begin{array}{l}\text { Ensuring a sine wave voltage output is ac- } \\
\text { counted during the machine de- } \\
\text { sign/construction phase. }\end{array}$ & $\begin{array}{l}\text { Sine-wave can be achieved through the use a } \\
\text { suitable modulator and reference waveform, but } \\
\text { any shape can be achieved as desired. }\end{array}$ \\
\hline $\begin{array}{l}\text { High short-circuit current due to low internal } \\
\text { impedances. }\end{array}$ & $\begin{array}{l}\text { Potential short-circuit current is high but pro- } \\
\text { tection against it must be provided in the form } \\
\text { of current limiting functions. }\end{array}$ \\
\hline $\begin{array}{l}\text { Current rating defined by the winding insula- } \\
\text { tion temperature rise. The thermal time con- } \\
\text { stant of the winding and surrounding material } \\
\text { is large and a useful short term over-rating is } \\
\text { available. Large thermal time constants allow } \\
\text { large fault currents for several main cycles. }\end{array}$ & $\begin{array}{l}\text { Current rating defined by the temperature rise } \\
\text { of the semiconductors, which have very low } \\
\text { thermal time constants. Large currents cause } \\
\text { semiconductor failure in less than } 1 \mathrm{~ms} \text {. The } \\
\text { cooling system has also low thermal time con- } \\
\text { stants, limiting the over-rating capabilities. In- } \\
\text { verter over-rating is necessary to accommodate } \\
\text { over-currents. }\end{array}$ \\
\hline $\begin{array}{l}\text { Real power exchange is dictated by the torque } \\
\text { applied to the shaft. Power sharing is based on } \\
\text { the use of control systems as a function of sys- } \\
\text { tem frequency. }\end{array}$ & $\begin{array}{l}\text { Real power exchange is dictated by the refer- } \\
\text { ences applied to the control system, subjected } \\
\text { to the DC-link capacity to sink the requested } \\
\text { power. }\end{array}$ \\
\hline
\end{tabular}

\subsubsection{PQ inverter control}

The PQ inverter is operated under a grid-connected mode and it should inject a given active and reactive power into the network, according to a set-point. In addition to active and reactive power flow control, this inverter is also responsible for the control of the DC-link voltage of the cascading DC/AC/DC system [21, 31]. Therefore, the magnitude and phase angle of the inverter voltage should be controlled in order to maintain the DC-link voltage at a specified reference and the reactive power output at the desired set-point. Neglecting losses, the power balance in the capacitor of the DC-link $\left(P_{C}\right)$ is the difference between the power received from the MS $\left(P_{M S}\right)$ and the inverter output power $\left(P_{i n v}\right)$, as shown in Fig. 11:

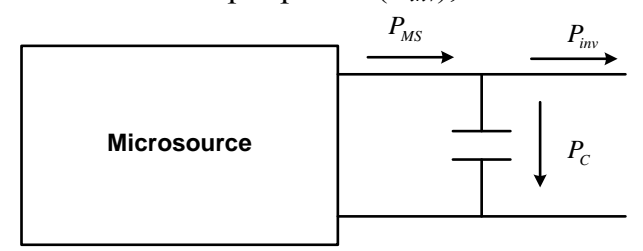

Fig. 11. DC-link capacitor power balance 


$$
P_{C}=P_{M S}-P_{i n v}
$$

The power flow in the DC-link capacitor can also be written as:

$$
P_{C}=V_{D C} \times I_{D C}
$$

where $V_{D C}$ is the DC-link voltage and $I_{D C}$ is the capacitor current. The DC-link voltage can be computed as:

$$
V_{D C}=\frac{1}{C} \int I_{D C} d t
$$

where $C$ is the value of the capacitance in the DC-link. Combining (21) and (22) and taking the Laplace transform, the DC-link dynamics can be modelled as depicted in Fig. 12.

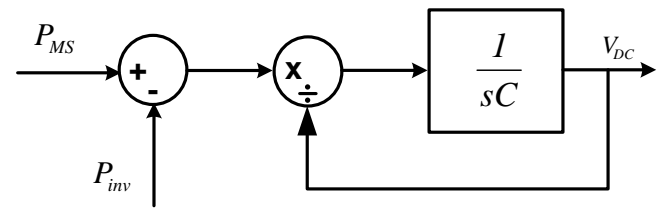

Fig. 12. DC-link dynamic model

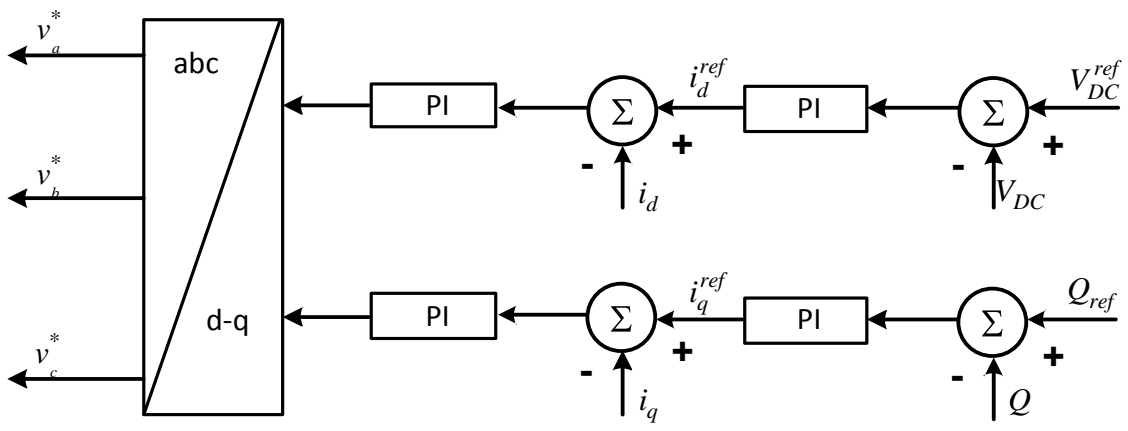

Fig. 13. Three-phase PQ inverter control

As previously mentioned, the control logic for the PQ inverter is associated to the control of the DC voltage in the DC-link capacitor. Under such approach, the DC voltage error is used in order to generate the $i_{d}$ current reference. The error that is generated between the reference value of reactive power and the actual injected power or between the reference voltage and the measured terminal voltage are used in order to generate the $i_{q}$ current reference. Afterwards, the inner current 
control loop based on a proportional-integral controller is used in order to generate the converter output voltages [7], as depicted in Fig. 13.

\subsubsection{Voltage source inverter control}

The VSI is used in order to interface a storage device (such a flywheel or a battery) with the AC grid. By making use of the energy stored in such devices, the VSI is able to emulate the behaviour of a synchronous machine, thus controlling voltage and frequency on the AC system [1, 2, 28, 32]. In conventional power systems, synchronous generators share any load increase by decreasing the frequency according to their governor droop characteristic. This principle can be implemented in inverters by decreasing the reference frequency when there in an increase in the load. Also, reactive power is shared by introducing a droop characteristic in the voltage magnitude. Therefore, the VSI acts as a voltage source, with the magnitude and frequency of the output voltage controlled through droops, as described in the following equations:

$$
\begin{aligned}
& \omega=\omega_{0}-k_{P} \times P \\
& V=V_{0}-k_{Q} \times Q
\end{aligned}
$$

where $P$ and $Q$ are the inverter active and reactive power outputs, $k_{P}$ and $k_{Q}$ are the droop slopes (positive quantities) and ${ }_{0}$ and $V_{0}$ are the idle values of the angular frequency and voltage (values of the inverter angular frequency and terminal voltage at no load conditions). When a VSI is interconnected with a stiff AC system, characterized by an angular frequency grid and terminal voltage $V_{\text {grid }}$, the voltage and frequency references are externally imposed [32]. In this case, the desired output powers $P_{1}$ and $Q_{l}$ can be obtained in the VSI output by adjusting the idle values of the angular frequency ${ }_{01}$ and voltage $V_{01}$ as follows (illustration in Fig. 14Fig. 14. Frequency versus active power droop

) :

$$
\begin{aligned}
& \omega_{01}=\omega_{\text {grid }}+k_{P} \times P_{1} \\
& V_{01}=V_{\text {grid }}+k_{Q} \times Q_{1}
\end{aligned}
$$




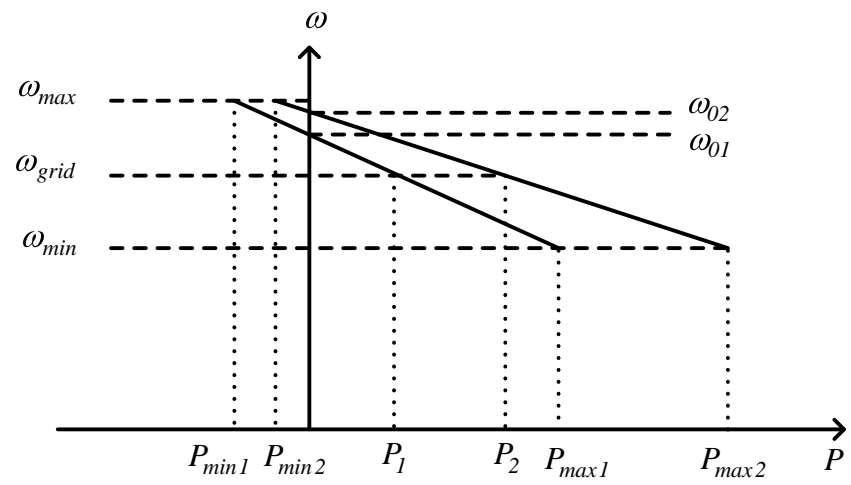

Fig. 14. Frequency versus active power droop

If a cluster of VSI operates in a standalone AC system, frequency variation leads automatically to power sharing, such that for a system with $n$ VSI the following equality stands:

$$
\Delta P=\sum_{i=1}^{n} \Delta P_{i}
$$

being $\Delta P$ the total power variation and $\Delta P_{i}$ the power variation in the $i$-th VSI. The frequency variation can be computed as:

$$
\Delta \omega=\omega_{0 i}-k_{P i} \times P_{i}-\left[\omega_{0 i}-k_{P i} \times\left(P_{i}+\Delta P_{i}\right)\right]=k_{P i} \times \Delta P_{i}
$$

Similar considerations can be made for the voltage/reactive power VSI control mode based on droops [28, 29]. However, as voltage has local characteristics, network cable impedances do not allow a precise sharing of reactive power among VSI.

In this chapter, a three-phase balanced model of a VSI implementing the described droop concepts is described. The model is derived from a single-phase version presented in $[32,33]$. The general block diagram of the control scheme is presented in Fig. 15. The VSI terminal voltage and current are measured in order to compute active and reactive powers. This measuring stage introduces a delay for decoupling purposes. The active power determines the frequency of the output voltage by the active power/frequency droop $k_{P}$. Similarly, the reactive power determines the magnitude of the output voltage by the reactive power/voltage droop $k_{Q}$. The output voltages are the reference signals that that are used in a second control stage responsible for inverter voltage and current regulation. 


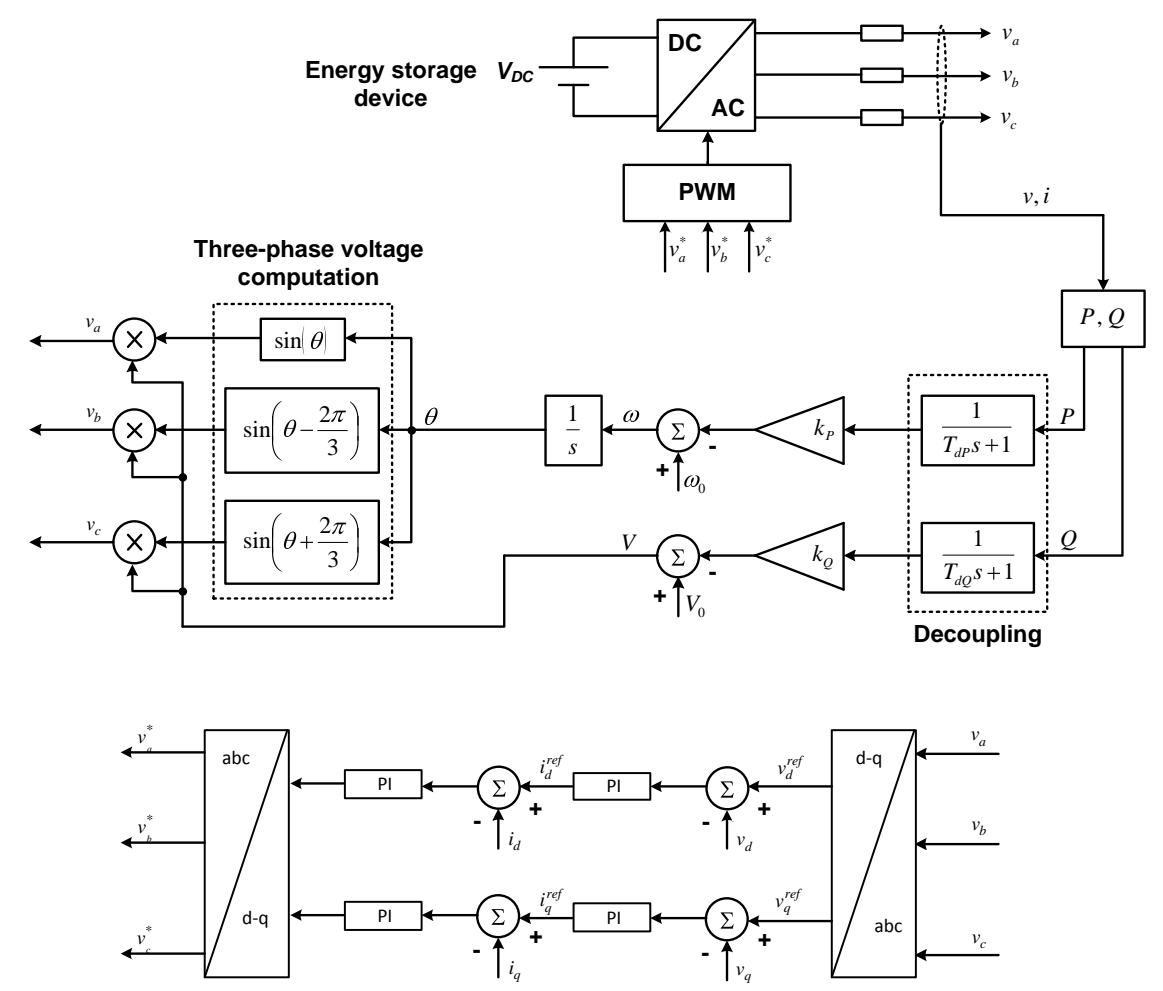

Fig. 15. VSI control model

\subsubsection{Inverter modelling during short-circuits}

Conventional power plants comprising synchronous generators directly connected to the grid provide large short-circuit currents, which are very helpful for fast and efficient fault detection and elimination. However, in a MG, where generation units are mainly connected to the grid through power electronic interfaces, it is difficult to obtain high fault currents. Solid state switching devices used in inverters are selected based on voltage, current carrying capability (under certain cooling conditions and for a defined switching frequency) and safe operating areas. The islanded system can ride through short-circuits if there is sufficient oversizing of power electronic interfaces in order to provide adequate short-circuit currents. At the same time, a novel protection scheme for the MG must be developed using different types of relays and breakers instead of conventional fuses [34]. Resulting from this explanation, the following considerations can be made [1]: 
- The VSI need to be up-rated in order to provide a significant contribution to short-circuit currents (ranging from 3 to 5 p.u.): therefore, VSI will be capable of providing fault currents during $\mathrm{MG}$ islanding operating conditions.

- PQ inverters provide only a small amount of short-circuit current (1.2 to 1.5 p.u.).

As described in the previous sections, the use of inner current control loops both for PQ controlled inverters and for VSI allows a simple and efficient control over the output inverter current during short-circuit conditions. Such limiting functionality can be performed through a limitation of the output of the PI controllers used on those current control loops.

\subsection{MicroGrids Emergency Control Strategies}

The successful design and operation of a MG requires solving a number of demanding technical issues related to system functions and controls. The presence of power electronic interfaces in fuel cells, photovoltaic panels, microturbines and storage devices is the distinguishing characteristics of a MG when compared with conventional systems using synchronous generators. The dynamic behaviour of a system like the MG, with very low global inertia, is also quite different from the one observed in conventional power systems. Conventional power systems have the possibility of storing energy in the rotating masses of synchronous generators, thus providing the required energy balance in the moments subsequent to a load connection. In case of MG islanded operation, load-tracking problems arise since microturbines and fuel cells have slow response to control signals (large time constants associated to these MS) and are inertia-less.

A system with clusters of MS designed to operate in islanded mode requires some form of energy buffering in order to ensure initial energy balance. The active power shortage caused in a MG when moving to islanding operation or resulting from load or power variations during the islanding operation mode must be compensated by energy storage devices. Additionally, the slow response of controllable MS to the control signals is a specific issue contributing to the need of providing some form of energy storage with fast response in terms of power injection capabilities in order to enable MG operation under islanded conditions. The necessary energy storage can be provided by batteries or supercapacitors connected on the DC bus of each MS or through the direct connection of independent storage devices to the LV grid (batteries; flywheels, supercapacitors) [1, 29, 30].

MG islanding may result from an intentional disconnection from the MV grid (for example, due to maintenance needs) or from a forced disconnection (due to a fault in the upstream MV network). Concerning an intentional disconnection, some control actions can be performed in order to balance load and generation in the MG and smooth the islanding transient. Following a disturbance in the up- 
stream MV network, MG separation must occur as fast as possible. Depending on the fault and on the load and generation profile in the MG, the switching transient will have different impacts on MG dynamics.

When the MG transfers to islanded operation, an immediate change in the output power control of the MS is required, as they change from a dispatched power mode to one controlling frequency in the islanded section of the grid. The control strategy to be adopted has to combine the frequency control strategy with the storage devices response and load shedding possibilities, in a cooperative way to ensure successful overall operation, although acting independently at the MC and LC level [1]. As it will not be common to find fully controllable synchronous generators in a $\mathrm{MG}$, inverter control is the main concern in $\mathrm{MG}$ operation.

If a system disturbance provokes a general blackout such that the MG is not able to separate and continue operation in islanding mode, and if the MV system is unable to restore operation in a predefined time, a first step in system recovery will be a local BS. The strategy to be followed involves the MGCC and the local controllers (LC and $\mathrm{MC}$ ), using predefined rules to be embedded in the MGCC software. Such an approach will enable fast restoration times to final consumers, thus improving reliability and reduce customer interruption times [2].

Another special feature of the MGCC concerns grid re-connection during BS, helping in this way the upstream DMS that is managing the MV distribution network. During faults on the main grid, the MG may be disconnected from the upstream MV network and will continue to operate with as much connected MS as possible. During grid reconnection, the issue of out-of-phase reclosing needs to be carefully considered. The development of local controllers in close coordination with the MGCC functions needs to be evaluated from the dynamic operation point of view. The strategies to be followed in order to deal with these two types of problems (MG black start and grid re-connection) will be embedded in the MG local controllers as a set of rules activated by the environmental conditions (characterized by the electrical variables voltage and frequency) and following orders from the MGCC.

\subsubsection{MicroGrid control for islanding operation}

If a cluster of MS is operated within a MG and the main power supply (the MV network) is available, all the inverters can be operated in the PQ mode because the voltage and frequency references are defined by the main system. In this case, a sudden disconnection of the main power supply would lead to the loss of the MG, since there would be no possibility for load/generation balancing, and therefore for frequency and voltage control. However, by using a VSI to provide a reference for voltage and frequency, it is thus possible to operate the MG in islanded mode and a smooth moving to islanded operation can be performed without changing the control mode of any inverter. This is possible since the VSI is able to operate in parallel with other voltage sources (for instance, the upstream MV network during 
MG normal operating conditions, or with other VSI during MG islanded operation) [1]. According to the VSI model previously described, it can react to network disturbances based only on information available at its terminals. This working principle of a VSI provides a primary voltage and frequency regulation functionality in the islanded MG. For example, considering a single VSI operating in an islanded grid, any power variation $\Delta P$ and $\Delta Q$ causes frequency and voltage variations that can be determined by:

$$
\begin{aligned}
& \Delta \omega=\omega_{0}-k_{P} \times P-\left[\omega_{0}-k_{P} \times(P+\Delta P)\right]=k_{P} \times \Delta P \\
& \Delta V=V_{0}-k_{Q} \times Q-\left[V_{0}-k_{Q} \times(Q+\Delta Q)\right]=k_{Q} \times \Delta Q
\end{aligned}
$$

After identifying the key issue for MG islanded operation, two main MG control strategies are possible: Single Master Operation (SMO) or Multi Master Operation (MMO) [1]. In both cases, a convenient secondary load-frequency control during islanded operation must be considered to be installed in controllable MS, as it will be descried later.

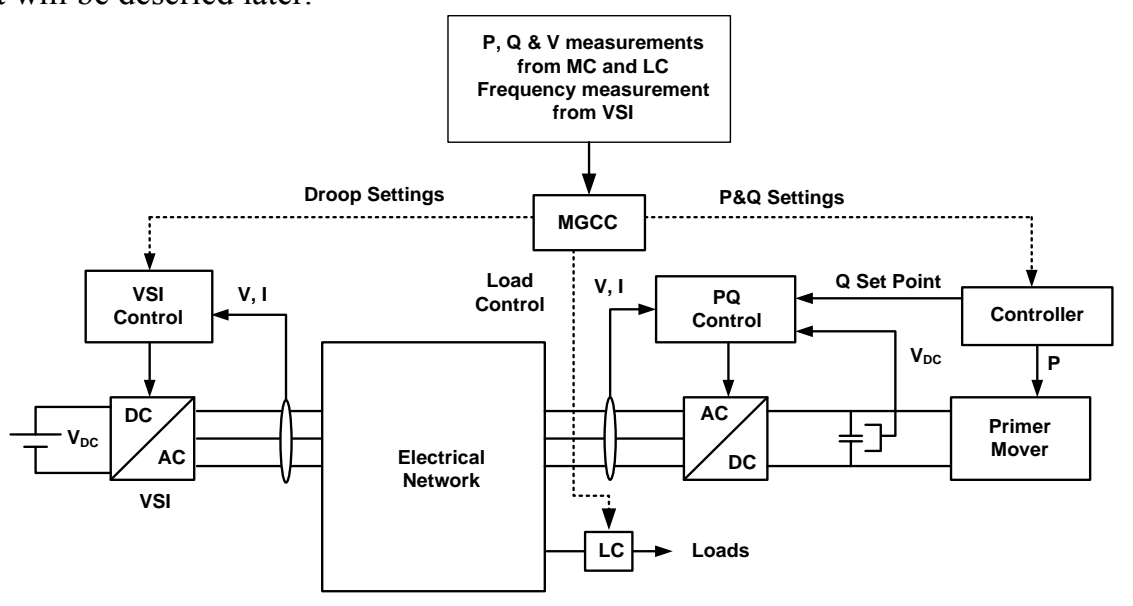

Fig. 16. Single Master Operation control scheme

\subsubsection{Single master operation}

The operation of a MG with several PQ controlled inverters and a single VSI can be defined as a SMO control strategy, and it is represented in Fig. 16. In this case, the VSI provides the voltage and frequency reference for the operation of the PQ controlled inverters when the MG is isolated from the main power supply.

The VSI is responsible for fast load-tracking during transients (natural variation of load and consumption, as well as during the islanding transient). Using the communication capabilities of the $\mathrm{MG}$, the MGCC receives information from $\mathrm{MG}$ 
local controllers and it is responsible for updating each PQ inverter set-point in order to achieve an optimal operation scenario regarding voltage levels, reactive power flows and active power dispatch. MGCC is also responsible for load control actions and for the definition of VSI droop settings.

\subsubsection{Multi master operation}

The operation of an isolated network with several VSI, as shown is Fig. 17, is similar to a conventional power system with synchronous generators controlling active power/frequency and reactive power/voltage. These functions are usually performed by conventional voltage and speed governors, which are now replaced by the droop characteristics: the frequency/active power and voltage/reactive power droops.

Considering the interconnected operation mode, the frequency of the LV grid is set by the external grid. Each inverter is operating with a pre-defined frequency/active power characteristic droop. The idle frequency $f_{0}$ of each VSI can be modified in order to define the desired value of the active power injected by the VSI. As the grid frequency fluctuations of the interconnected system are very small, the idle frequency can be used in order to dispatch generation [32]. This function can be performed by the MGCC, and requires a periodic actualization of several parameters in accordance with the operational criteria used in the MGCC algorithms.

If a fault causes the transition from the interconnected to the islanded mode, it is not necessary to change the control strategies of each MS. When the main power supply is disconnected, the overall system moves to a new operation point (in voltage and frequency), depending on the local load. Then, a secondary control strategy can be made to act on the inverter in order to restore the nominal value of the frequency.

\subsubsection{Emergency strategies}

In case of a fault in the upstream MV network or in other special operating conditions it is necessary to exploit the possibility of moving the MG into an islanding operating mode. This control approach constitutes a solution opposed to the current practice of not allowing distribution grids with embedded generation to be operated isolated from the main power system. The islanding procedure is therefore regarded as possible operation state and it requires a careful planning of the system conditions in respect to load, MS production levels, existence of faults, etc. In order to ensure system survival following islanding it is necessary to exploit controllable MS, storage devices and load shedding mechanisms in a cooperative way, as described next. 


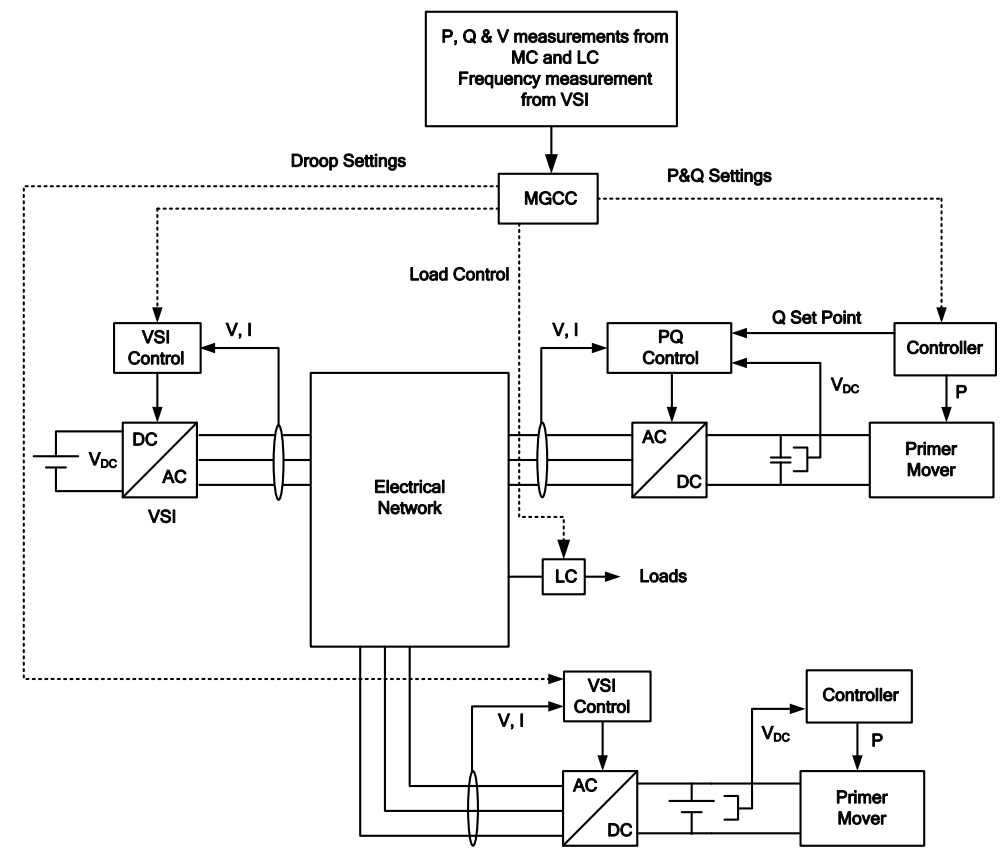

Fig. 17. Multi Master Operation control scheme

\subsubsection{Frequency control}

In terms of standalone AC system operation, the VSI control principle makes possible reacting to system disturbances (for example load or generation changes) based only on information available at its terminals (voltage and current measurements, according to its control model shown in Fig. 15). In this way, the operation of a MG does not rely on fast communications among MS controllers and the MGCC, which could be impractical. Running in a larger time frame, a secondary control approach can be used to improve system performance, namely restoring nominal frequency values during islanding operation.

Equation (27) shows that the VSI active power output is proportional to the MG frequency deviation. In the moments subsequent to MG islanding or due to loads or power variations during MG islanding operation, the first devices reacting to the new system conditions are the VSI coupled to storage devices [1]. Acting as a voltage source, power imbalance following a disturbance demands larger currents from the VSI, therefore increasing its measured output power. As a consequence of the increase in the VSI output power, the MG frequency decreases in accordance to the active power/frequency droop, as illustrated in Fig. 18. Let's consider in a first place a SMO strategy. When the MG is interconnected with the upstream MV network the storage device is injecting an active power $P_{0}$. In the 
moments subsequent to MG islanding, the frequency drifts towards a new value ${ }_{l}$ and the power injected by the VSI increases to $P_{l}$. The difference between the power injected after islanding $P_{1}$ and the power injected previous to islanding $P_{0}$ is $\Delta P=P_{1}-P_{0}$ and corresponds to the amount of power absorbed from the upstream MV network during the interconnected operation mode. In other words, $\Delta P$ is the power imbalance between MG local load and generation following islanding.

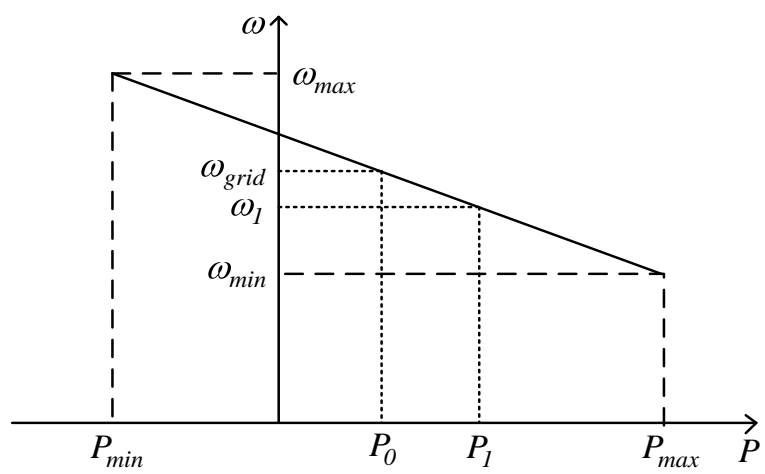

Fig. 18. VSI frequency decrease due to active power increase

In case of a MMO strategy ( $n$ VSI operating in parallel in a standalone AC system), a power variation $\triangle P$ in the system is shared among the VSI, according to (25). Previous to MG islanding, all the VSI are operating at the same frequency, which is equal to the grid frequency. Combining all the droop characteristics of the VSI inverters, the steady state power variation in each VSI and system frequency in the moments subsequent to the disturbance can be computed using the following matrix equation:

$$
\left[\begin{array}{cccccc}
1 & k_{P 1} & 0 & 0 & \cdots & 0 \\
1 & 0 & k_{P 2} & 0 & \cdots & 0 \\
1 & 0 & 0 & k_{P 3} & \cdots & 0 \\
\cdots & \cdots & \cdots & \cdots & \ddots & \vdots \\
1 & 0 & 0 & 0 & \cdots & k_{P n} \\
0 & 1 & 1 & 1 & \cdots & 1
\end{array}\right] \times\left[\begin{array}{c}
\omega^{\prime} \\
\Delta P_{1} \\
\Delta P_{2} \\
\Delta P_{3} \\
\vdots \\
\Delta P_{n}
\end{array}\right]=\left[\begin{array}{c}
\omega_{\text {grid }} \\
\omega_{\text {grid }} \\
\omega_{\text {grid }} \\
\vdots \\
\omega_{\text {grid }} \\
\Delta P
\end{array}\right]
$$

where ' is the post-disturbance MG angular frequency and grid $=0_{i}-k_{P i} \times P_{i}$ is the pre-disturbance MG angular frequency. Using (28) it is possible to compute MG frequency deviation $\Delta=$ '- grid and the power sharing among the VSI following a generation or load variations $\Delta P$ during islanding conditions. 
In both cases, it is possible to conclude that the VSI action following disturbances during islanding operation can be regarded as a primary frequency control, similarly to what happens in synchronous generators assigned to primary frequency control in conventional power systems.

In addition to this primary frequency control functionality, controllable loads plays an important role under some MG operating conditions, namely those concerning the imbalance between load and generation (load larger than generation). In order to deal with this problem, a load shedding mechanism can be implemented in a MG as an emergency functionality to aid frequency restoration to its nominal value after MG islanding [1]. Load shedding is used as a remedy against large frequency excursions. Basically, the dynamic behaviour of the system is improved if some percentage of the load is temporarily lost, allowing the generators with frequency regulation functions to react to the frequency deviation. The benefits derived from such a scheme are well known, particularly in what concerns a rapid reaction following a large frequency deviation, leading to a faster stabilization of the system and to the frequency restoration to its nominal value. Following MG recovery after islanding, some loads that were disconnected by load shedding relays can be reconnected again. In order to avoid large frequency deviations during the load reconnection, it is necessary to implement adequate load reconnection mechanisms (for example, load reconnection based in small steps) in order to avoid large frequency deviations during this stage. All this functionalities can be easily implemented in LC.

These considerations show that during MG islanding operation the frequency drifts from the nominal value following power or load variations. During this transient condition, power balance in the MG is assured by energy storage devices. However, if the MG frequency stabilizes in a value different from the nominal one, (due to the use of only proportional droop controls) storage devices would keep on injecting or absorbing active power whenever the frequency deviation differs from zero. This situation is illustrated in Fig. 19, where it is shown VSI power injection as a function of MG frequency deviation. The figure illustrates that power injection is proportional to $M G$ frequency deviation (within the power ratings of the storage device). This should be only admissible during transient situations, where storage devices are responsible for ensuring the energy balance between load and generation within the MG. However, storage devices (batteries, flywheels or supercapacitors with high capabilities for injecting power during small time intervals) have a finite storage capacity and can be loaded mainly by absorbing power from the LV grid. Therefore, they should inject power into the MG only during transient situations in order to not run out of energy. Consequently, the development of a control procedure to correct permanent frequency deviations during any islanded operating conditions should then be considered as one of the key objectives for any control strategy. 


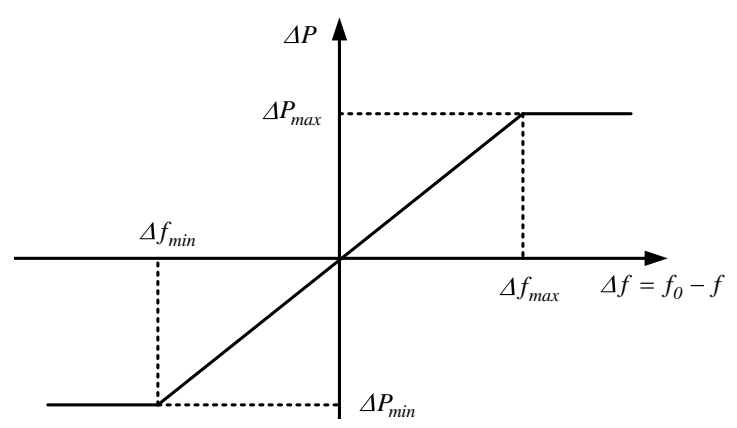

Fig. 19. Steady state active power characteristic of a VSI coupled to a storage device

In order to promote adequate secondary control aiming to restore frequency to the nominal value after a disturbance, two main strategies can be followed: local secondary control, by using a PI controller at each controllable MS (Fig. 20), or centralized secondary control mastered by specific algorithms to be embedded in the MGCC software modules [1]. In this chapter, a simple approach is described, based on a local secondary control strategy. In both cases, target values for active power outputs of the primary energy sources are defined based on the frequency deviation error. For SMO, the target value is directly an active power set-point sent to the prime mover of a controllable MS, while for MMO, the target value can be both an active power set-point for a controllable MS connected to a PQ inverter or a new value for the idle frequency of a VSI connected to a MS with storage devices in the DC-link.

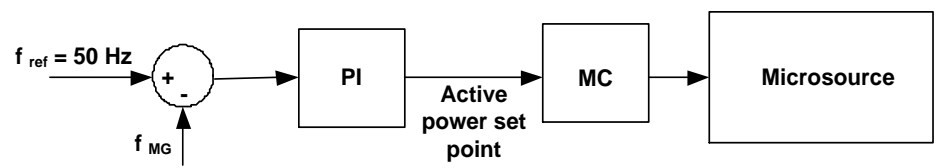

Fig. 20. Local secondary load-frequency control for controllable MS

\subsubsection{Exploiting low voltage MicroGrids for service restoration}

Although DG has been increasing significantly in the recent years, there is little work on the identification of its contribution for power systems restoration. Conventional restoration procedures focus on the restoration of bulk power transmission systems and its loads. The current practice for DG integration in electrical power systems is based on the principle that DG should not jeopardize the power system to which it is connected and it should be quickly disconnected following any disturbance. Additionally, it is only reconnected when distribution circuits are energized and its voltage and frequency profiles are stable. 
Power system conventional restoration procedures are usually developed before any emergency situation occurs, adopting heuristic approaches, which reflect human operators experience to deal with the problem. Furthermore, the size and specific characteristics of actual power systems precludes the definition of an universal methodology [35]. The restoration plan is defined step by step, based on predefined guidelines and operating procedures, sometimes exploiting decision support tools, which are an extremely valuable resource to assist system operators [36]. The restoration procedure is focused on the plant preparation for restart, network energization and system rebuilding. Depending on system characteristics, a choice must be made between a strategy of energizing the bulk network before synchronizing most of the generators or a strategy of restoring islands that will be synchronized later [37].

In order to exploit the new possibilities offered by the increasing amounts of DG units connected to electrical power systems, new approaches are required in order to make possible DG participation in several system services, such as power system restoration. In this scenario, it would be possible to develop a new restoration process that will run simultaneously in the transmission and distribution system. Such a strategy will exploit the conventional power system restoration strategy in the upstream transmission level, while the energization of some islands by means of DG units will allow expanding service restoration at the downstream distribution level based on the availability of DG units with BS capability. Contrary to what are the current restoration strategies followed by the utilities, (wait several hours for the restoration at the transmission level before restoring service in the distribution level and allow DG connection), DG could allow the formation of several distribution network cells through the exploitation of DG black start capabilities. The coordination between the upstream and downstream restoration will allow a better service continuity, increasing the amount of restored load and shortening the electric power system restoration times [2, 38].

Concerning the MG concept, the reduction of LV consumers interruption time can be performed by allowing MG islanded operation until MV network is available and by exploiting MG generation and control capabilities to provide fast BS at the LV level. If a system disturbance provokes a general or local blackout, such that the MG is not able to successfully separate and continue to operate in islanded mode, and if the MV network is unable to restore operation within a pre-defined time, a first step in system recovery will be a local BS in the LV grid. This first step will be afterwards followed by the MG synchronization with MV grid. Based on the MG control strategies previously described and making use of the MG communication infrastructures, special issues for MG service restoration are identified in order to totally automate MG restoration procedure. Within a MG, local self-healing techniques can be derived, since MG can be used for service restoration in their area of influence. The entire power system restoration procedure can then exploit a simultaneous bidirectional approach: a conventional top down strategy, starting from large plant restart and transmission energization, and simultaneously a bottom-up strategy, starting from the distribution side and exploiting DG 
units and microgeneration capabilities. Synchronization among these areas follows afterwards. This approach helps to reduce restoration times and to reduce the unserved electric energy during major failures [2].

During conventional power system restoration, a set of critical issues should be addressed carefully: reactive power balance, switching transient voltages, load and generation balance and coordination, sequencing of generating units start-up and definition of the relays settings [39]. In case of a MG, the restoration procedure is much simpler due to the reduced number of controllable variables (switches, MS and loads). On the other hand, it is important to stress it will not be expectable to find conventional synchronous machines in a MG, which are liable for voltage and frequency control in conventional power systems. As previously referred, most of the MS currently available are not suitable for direct connection to the LV grid, requiring power electronic interfaces. Another special issue related to MS operation concerns its slow response to the control signals in order to change the output power. The absence of synchronous machines connected to the LV grid requires that power balance during transients should be provided by energy storage devices. Furthermore the controllability characteristics of the power electronic interfaces used in MS contributes to the definition of very specific restoration strategies.

\subsubsection{MicroGrid black start}

Based on the MG control strategies previously discussed and making use of the MG communication infrastructures, this section tackles the description of special issues for MG service restoration in order to totally automate the entire procedure. The MG black start will be centrally guided by the MGCC software. Under this philosophy, the BS software module is responsible for controlling a set of rules and conditions to be checked during the restoration stage, which should be identified in advance. These rules and conditions define a sequence of control actions to be carried out during the restoration procedure. The main steps to be considered include building the LV network, connecting MS, controlling voltage and frequency, connecting controllable loads and MG synchronization with the upstream MV network when it becomes available [2].

The MG restoration procedure will be triggered if a general or local blackout occurs or if major injuries affecting the MV network do not allow feeding the MG from the MV side after a pre-defined time interval. The MGCC should also receive information from the DMS about the service restoration status at the MV level in order to help deciding to launch the local BS procedure. The flow chart shown in Fig. 21 delineates the procedure followed by the MGCC to detect the occurrence of a blackout and decide when to trigger the MG black start procedure. 


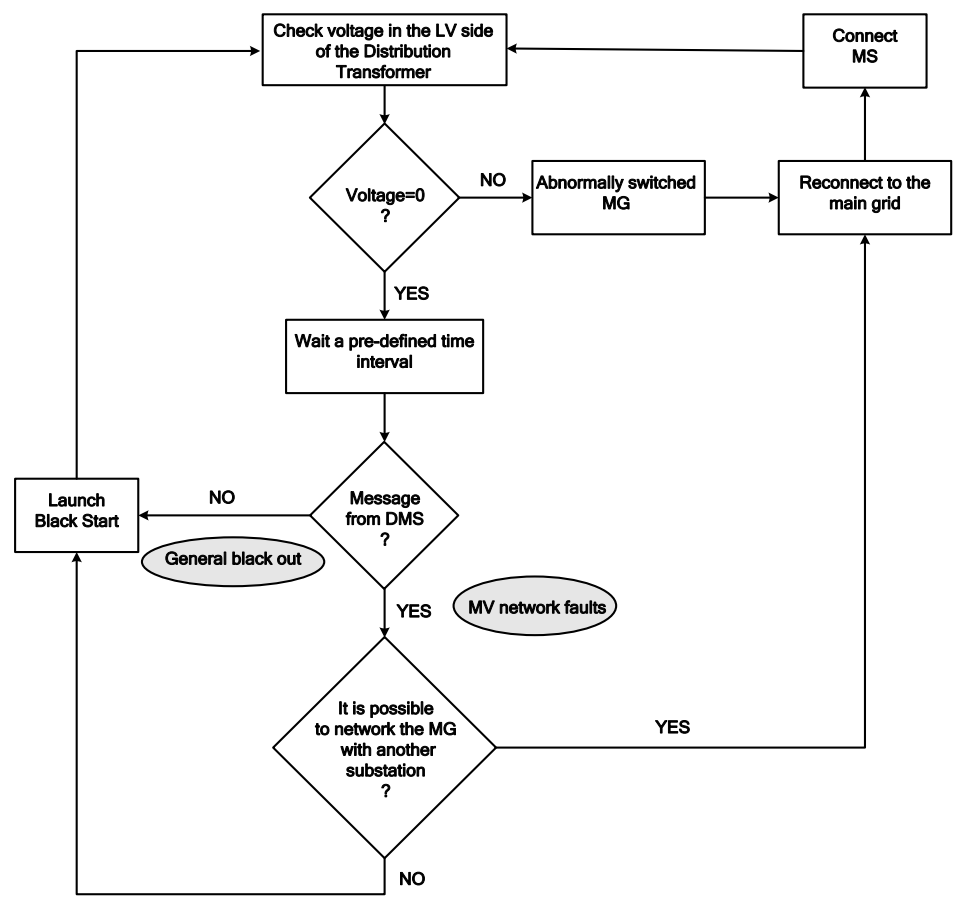

Fig. 21. Flow chart defining the conditions to trigger MG black start procedure

\subsubsection{General requirements for MicroGrid black start}

MG local controllers and the MG communication infrastructure are of utmost importance for the success of the restoration procedure. Thus, small auxiliary power units are required to power the communication network elements and local controllers (LC and MC). Another basic requirement is the availability of MS with BS capability, which involves an autonomous power supply to launch this kind of generation. Regarding SSMT technology previously described, it presents the capability of autonomous black start without being connected to the grid, if a battery pack is installed in the unit. MS restart procedure is carried out previously to building the LV network so it is not reflected in the LV network. Beyond this essential condition, it is also required availability for:

- Updated information, obtained before disturbance, about the status of load/generation in the MG and about availability of MS to restart. During normal operation, the MGCC periodically receives information from the LC and $\mathrm{MC}$ about consumption levels and power generation, storing this information in a database. It also stores information about technical characteristics of the different MS in operation, such as active and reactive power limits. This informa- 
tion will be used to restore the critical loads of the consumption scenario before blackout occurrence.

- Preparing network for re-energization. MG loads and generators must be disconnected from the LV grid after system collapse. Also, the MV/LV distribution transformer should be disconnected from the LV and MV networks.

During the BS procedure development, MS with BS capability are the SSMT and the MG energy storage units. At least during the first stages of this sequence, a multi master control approach needs to be adopted, since several VSI can operate in parallel and therefore will increase system robustness. Later, this strategy can be turned into a SMO in the final stages of the BS procedure.

\subsubsection{Sequence of actions for MicroGrid black start}

After a general blackout, the MGCC will perform service restoration in the LV area based on the information stored in a database about the last MG load scenario, as described before, by performing the following sequence of actions [2]:

- Sectionalizing the MG around each MS with BS capability in order to allow it to feed its own (protected) loads. These actions lead to an initial creation of small islands inside the MG, which will be all synchronized later. In this case, each MS with BS capability is running and feeding a load, which helps to stabilize its operation.

- Building the LV network. The MG main storage device is used for energising an initial part of the LV network, followed by switching on all the remaining LV switches not connected to loads or MS. An additional issue during LV energization is related to MG neutral earthing, since the TN-C-S system is suggested to be adopted [34]. MG neutral earthing should be created at the MG storage unit.

- Small islands synchronization. MS already in standalone operation mode should then be synchronized with the LV network. The synchronization conditions (phase sequence, frequency and voltage differences) should be verified by local MC, after the procedure is enabled by the MGCC, in order to avoid large transient currents which may compromise inverters operation.

- Connection of controllable loads to the LV network is performed if the MS running in the LV network has the capability to supply these loads. The amount of power to be connected should take into account the available storage capacity in order to avoid large frequency and voltage deviations during load connection. Motor load starting is a critical issue due to the large current absorbed in the first moments.

- Connection of non-controllable MS or MS without BS capability, such as PV and micro wind generators. At this stage, the system MS are sufficiently loaded in order to smooth voltage and frequency variations due to power fluctuations in non-controllable MS, so they can now be connected. LV network paths can 
also be created so that MS without BS capability can absorb power from the grid in order to restart.

- Load increase. In order to feed as much load as possible, depending on generation capability, other loads can then be connected. Motor load start-up is a critical issue due to the large current absorbed in the first moments. Large motor loads must be connected when the main MS are feeding the LV grid in order to increase the short-circuit power.

- Changing the control mode of MS inverters. The MG main storage inverter is controlled as a VSI, providing system voltage and frequency references. Then the MS with BS capability inverters operated as VSI may be changed to PQ control.

- $M G$ synchronization with the $M V$ network when it becomes available. The synchronization conditions should be verified again, after the order is given by the MGCC. This means the distribution transformer should be previously energized from the MV side, being the synchronization then performed through LV switches.

During MG restoration stages, special attention should be given to frequency. The frequency control principles previously described should be used in order to guarantee stable operating conditions.

\subsection{Application Example}

In the previous sections were described MS modelling details and the control strategies to be adopted in a MG when the system becomes isolated or it has to deal with a BS situation. The main objective of this section is to illustrate the performance of the control strategies previously described through the analysis of an application example. Therefore, a simulation platform was developed under the MatLab®/Simulink ${ }^{\circledR}$ environment, where MS models and MG control strategies for islanding operation were implemented.

\subsubsection{Moving to islanding operation}

The single line diagram of the LV test system used in this example is shown in Fig. 22. This LV test system is composed by a MV/LV distribution transformer and two LV distribution feeders. A LV distribution feeder is used to supply an industrial consumer, which has connected two $30 \mathrm{~kW}$ SSMT (SSMT 1 and SSMT 2). The industrial consumer load is composed by a mix of induction motor loads and constant impedance loads. The other LV feeder is used to supply a residential area with two apartment buildings and a group of residences. Within the residential area there are several microgeneration technologies connected to the grid. It 
was also assumed that some residential loads are to be modeled as induction motor loads. The MG main storage device (a flywheel, battery or supercapacitor) is connected through a LV cable to bus 1 and it is indented to allow MG running into islanding operation. The MG separation device is assumed to be the LV breaker located in the LV side of distribution transformer. The MG peak load is around 170 $\mathrm{kVA}$, while the total MS installed capacity is $155 \mathrm{~kW}$ (storage device is not considered since it only injects energy in the grid during transient situations). As the total MS capacity is not able to cover the MG peak load, MG islanding can only take place if it assumed the possibility of disconnecting some loads in the moments subsequent to MG islanding.

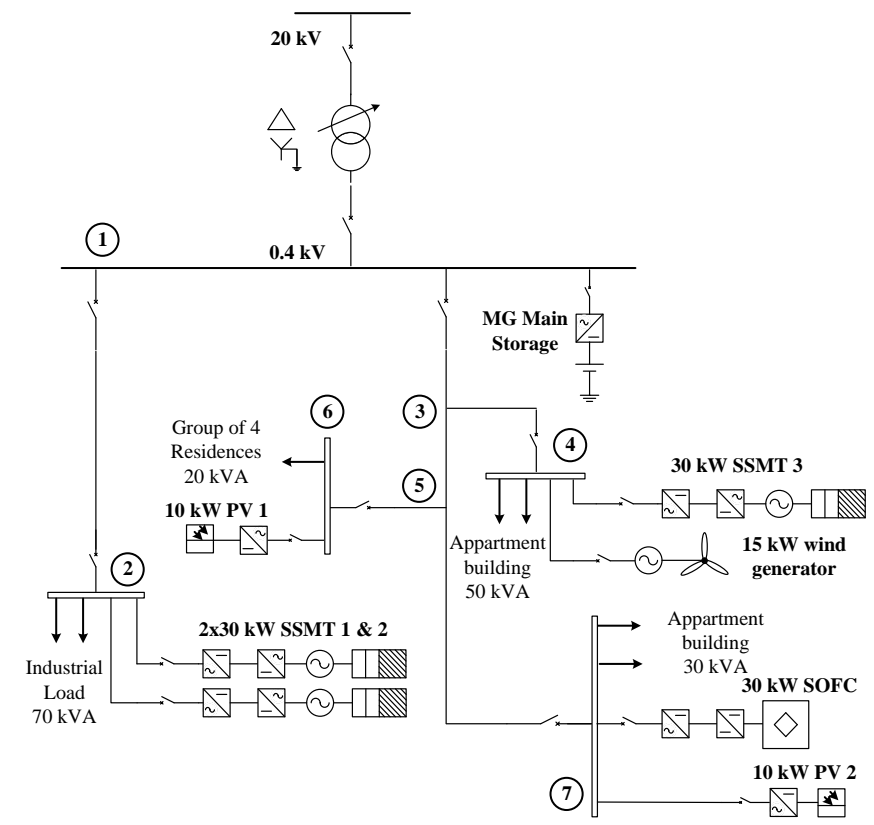

Fig. 22. $M G$ test systems for studding $M G$ islanding operation

Disconnection from the upstream MV network and load-following in islanded operation was simulated in order to illustrate the dynamic behaviour of the MG and the effectiveness of the control functionalities. MG islanding can occur in two different situations: scheduled islanding and forced islanding (resulting from faults in the upstream MV grid). For illustration purposes, results from forced islanding due to faults in the MV grid are presented next. In this scenario the SOFC and the SSMT are supposed to be the controllable MS used for the secondary loadfrequency control.

In other to illustrate the performance of the MG emergency control strategies, two operating scenarios were defined: Table 2 summarizes each scenario regarding $\mathrm{MG}$ power generation and the decomposition of MG load in terms of constant 
impedance load and induction motor loads. A single master operation strategy is considered in this example (a single VSI is connected to the MG, as it is shown in Fig. 22). The simulation results shown in Fig. 23 and Fig. 24 show the MG dynamic behavior after a three-phase fault occurring in the MV network at $t=10 \mathrm{~s}$, which is followed by MG islanding in $100 \mathrm{~ms}$ (MG islanding takes place at $\mathrm{t}=$ $10.1 \mathrm{~s})$

Table 2. Characterization of MG operating scenarios

\begin{tabular}{lllllll}
\hline \multirow{2}{*}{$\begin{array}{l}\text { Scenario } \\
\text { Loads }\end{array}$} & \multicolumn{2}{l}{$\begin{array}{l}\text { Constant Impedance } \\
\text { Loads }\end{array}$} & \multicolumn{2}{l}{$\begin{array}{l}\text { Induction Motor } \\
\text { Loads }\end{array}$} & \multicolumn{2}{l}{ MS Genation } \\
\cline { 2 - 7 } & $\mathrm{P}(\mathrm{kW})$ & $\mathrm{Q}(\mathrm{kvar})$ & $\mathrm{P}(\mathrm{kW})$ & $\mathrm{Q}(\mathrm{kvar})$ & $\mathrm{P}(\mathrm{kW})$ & $\mathrm{Q}(\mathrm{kvar})$ \\
\hline 1 & 112.2 & 38.3 & 24.9 & 16.1 & 138.2 & 54.7 \\
2 & 80.1 & 27.2 & 24.9 & 16.3 & 105.6 & 43.4 \\
\hline
\end{tabular}

Following MG islanding, the frequency drifts from the nominal value due to the load and generation unbalance. The results show that the MG main storage device is responsible for the balance of local load and generation in the moments subsequent to the islanding; at the same time, controllable MS participate in frequency restoration using the PI control strategy previously described and its power output increases according to their dynamic time constants. The large time constants of the MS lead to a relatively slow process for restoring frequency to its nominal value. Following the power increase in the controllable MS, storage devices progressively reduce its power output while MG frequency is increasing towards the nominal value. The storage device is responsible for matching local load and generation during this process. Its contribution in terms of active power injected in the MG and its evolution according to the MG frequency is also shown in Fig. 23.

MG frequency in the moments subsequent to islanding has a long period with a quite pronounced deviation from the nominal value. Load shedding mechanisms can be used as an emergency action against large frequency excursions. Basically, the dynamic behavior of the system is improved if some percentage of the load is temporarily disconnected. The implementation of automatic and local load shedding mechanisms is based on four load disconnection steps that can be independently parameterized (each load disconnection step corresponds to a certain deviation in the system frequency). Table 3 shows the settings adopted for the load shedding mechanisms installed in controllable loads (load shedding is applied in constant impedance loads connected to buses 2 and 7). 

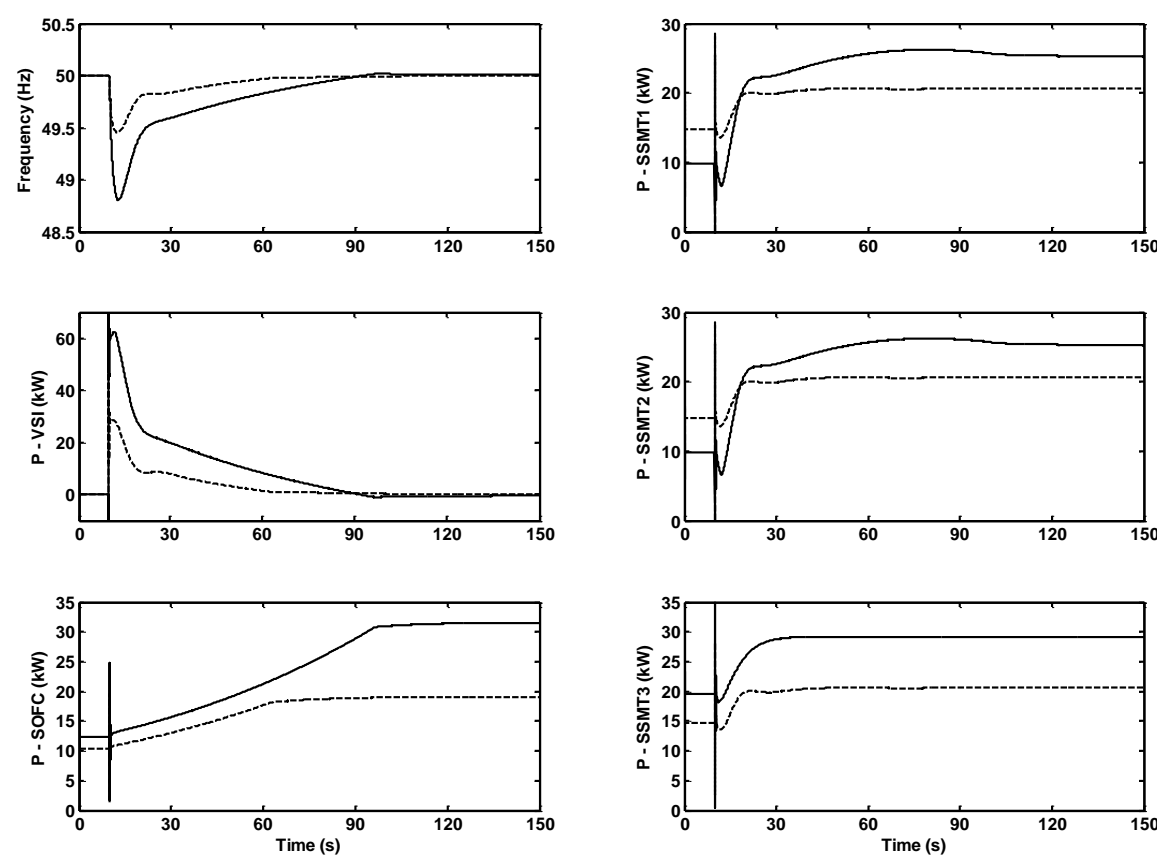

Fig. 23: MG frequency and controllable MS active following MG islanding, considering droop control and secondary active power/frequency control in scenario 1 (solid line) and scenario 2 (dash line)

Table 3. Settings for load shedding mechanisms in controllable loads

\begin{tabular}{ll} 
Frequency deviation $(\mathrm{Hz})$ & Load shedding $(\%)$ \\
\hline 0.25 & 30 \\
0.50 & 30 \\
0.75 & 20 \\
1.00 & 20 \\
\hline
\end{tabular}

The combined effect of primary frequency control, secondary load-frequency control and load shedding mechanisms is shown in the next figures. Due to the large initial frequency deviation following MG islanding, an amount of load is automatically shed through the activation of under frequency load shedding relays installed in LC. As it can be observed in Fig. 24Fig., the introduction of load shedding mechanisms significantly reduces frequency deviations following $\mathrm{MG}$ islanding in comparison with the case where the load shedding mechanisms are not considered. The amount of load that was automatically shed in buses 2 and 7 is around $46+j 17 \mathrm{kVA}$ in scenario 1 and $17+j 7 \mathrm{kVA}$ in scenario 2 . 

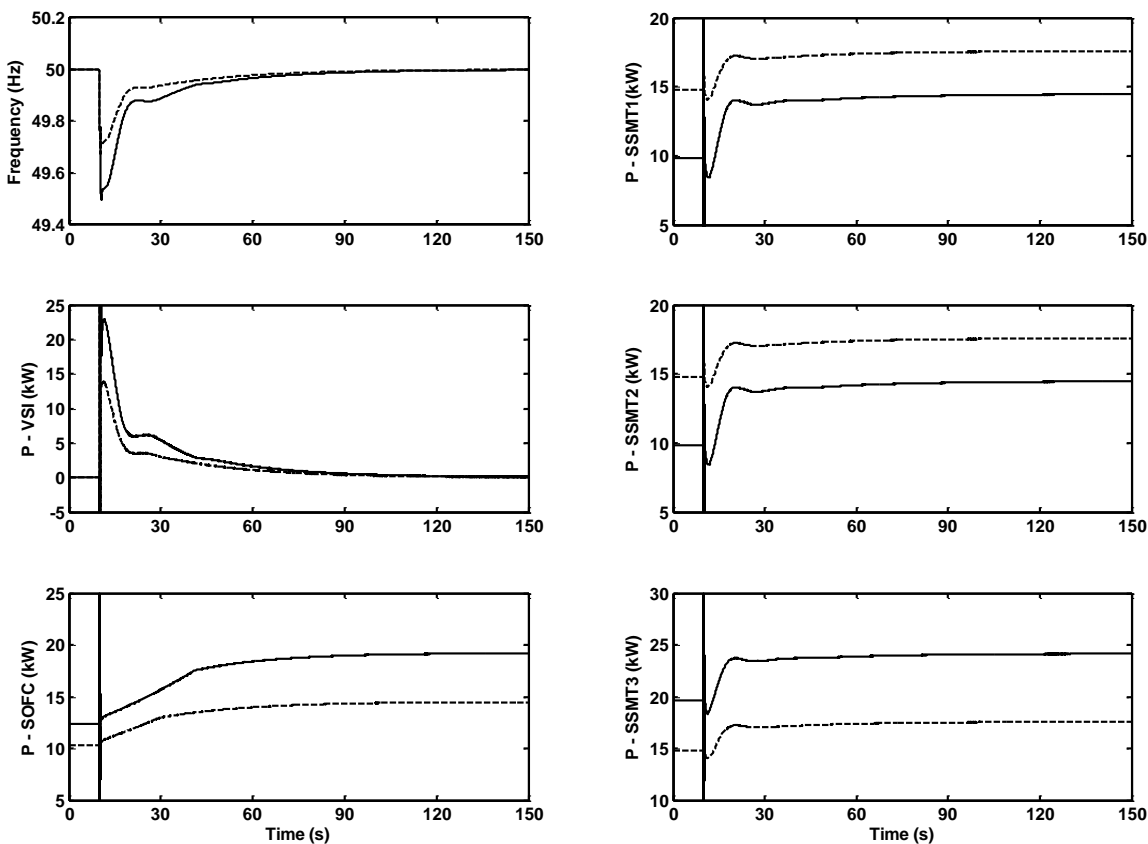

Fig. 24: $M G$ frequency and controllable MS active power following MG islanding in scenario 1 (solid line) and scenario 2 (dash line)

Following MG islanding, the natural load and generation variations need to be accommodated in order to ensure stable operation. Concerning scenario 2 previously described, the effects of load step connection were evaluated during $\mathrm{MG}$ islanding operation. Firstly, the loads that were disconnected due to the action of under frequency load shedding relays assumed to be installed in LC can be reconnected. Depending on the amount of load that was disconnected, a procedure based on a smooth step load connection should be used in order to avoid large frequency deviation that might compromise load reconnection. Load that was shed following MG islanding was reconnected in two steps at $t=160 \mathrm{~s}$ and $\mathrm{t}=190 \mathrm{~s}$, as can be observed in Fig. 25. Later, at $\mathrm{t}=250 \mathrm{~s}$, a $25+j 6 \mathrm{kVA}$ load was connected and disconnected at $\mathrm{t}=400 \mathrm{~s}$. As can be observed from the obtained results, the MG primary and secondary frequency control strategies ensure a stable operation in load following conditions. 

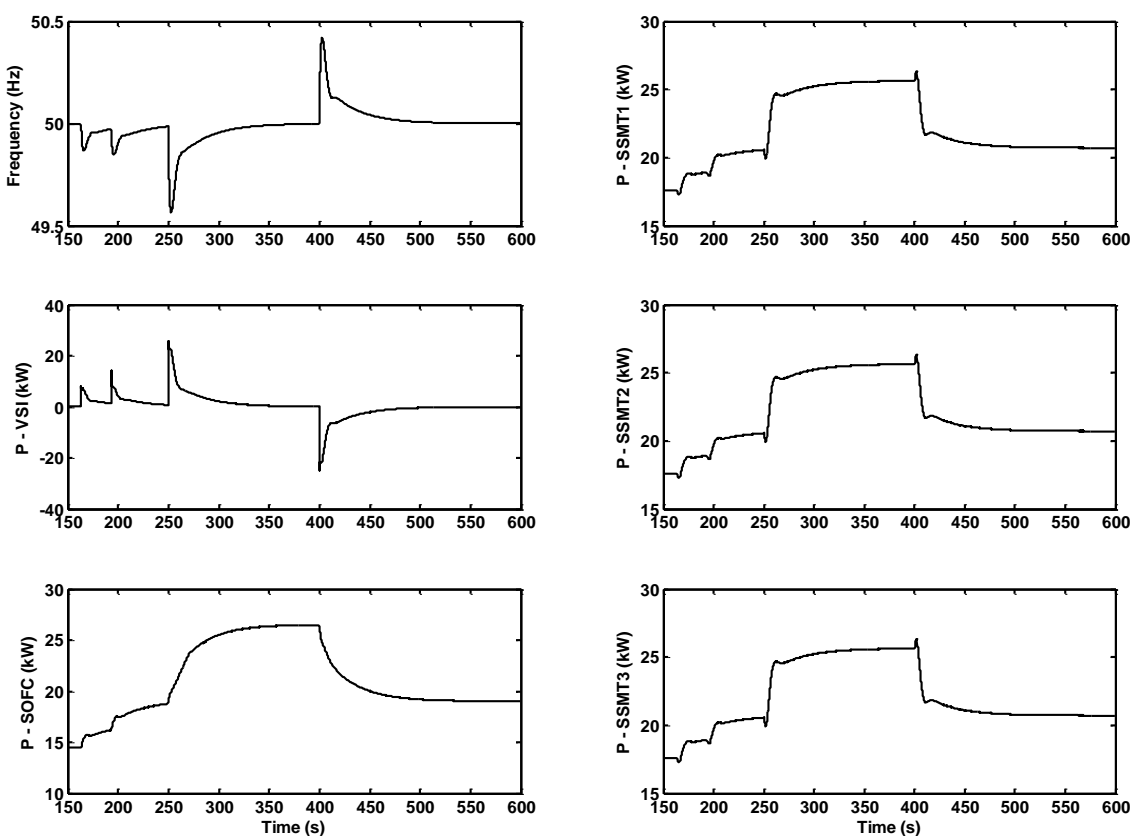

Fig. 25: MG frequency and controllable MS active power during islanding operation (load following)

\subsubsection{MicroGrid black start}

The LV voltage test system used in order to evaluate the performance of the MG restoration plan is shown in Fig. 26. The modifications introduced comparatively to the test system shown in Fig. 22 results from the types of MS used for this case, since SOFC are not suitable for a fast start-up following shut down. Therefore, the SOFC was substituted by a SSMT. Without loose of generalization, SSMT 1 and SSMT 2 in Fig. 22 were combined in an equivalent microturbine, with rated capacity of $60 \mathrm{~kW}$.

In order to illustrate the MG service restoration procedure, it is assumed that all microturbines restarted successfully following the general blackout. The initial steps of the restoration procedure consist on the connection of the SSMT protected loads, as shown in Fig. 27 at $t=5 \mathrm{~s}, \mathrm{t}=10 \mathrm{~s}$ and $\mathrm{t}=15 \mathrm{~s}$. Following the load connection to each SSMT operating autonomously, the frequency drifts according to the droop characteristic used in each VSI. Frequency deviation after load reconnection is a critical issue in this procedure, thus requiring a special attention. In order to maintain $\mathrm{MG}$ frequency within thigh limits $( \pm 0.2 \mathrm{~Hz})$, a local secondary control is used to restore MG frequency to nominal value. This secondary control 
is used to define the values of the VSI idle angular frequency as a function of frequency deviation.

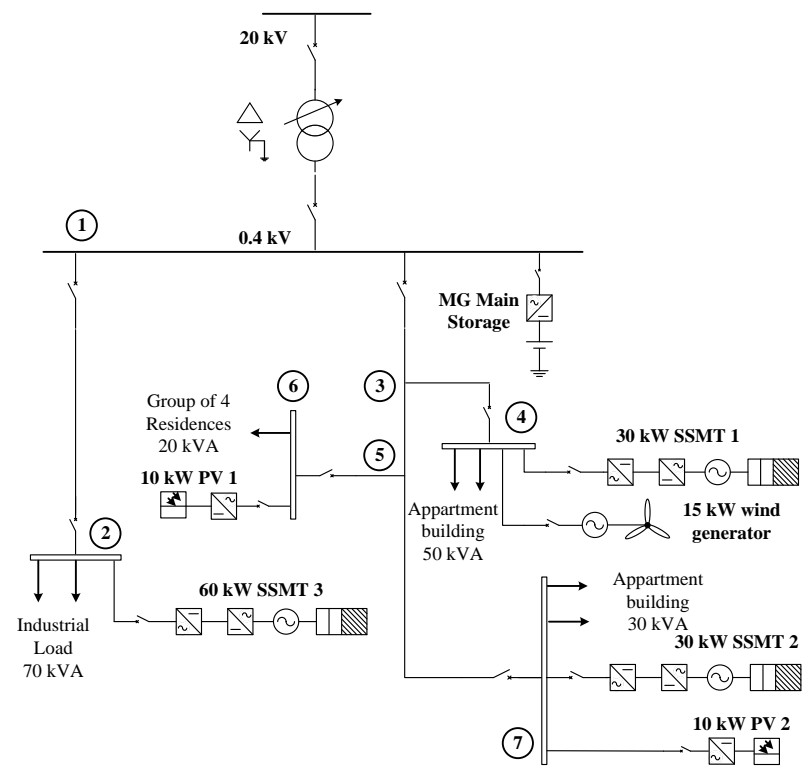

Fig. 26. $M G$ test systems for studding $M G$ restoration procedure

Following the energization the LV network and the connection of SSMT protected loads, the restoration procedure consists on the following sequence of actions:

- Synchronizing the SSMT 1 with the LV network $(\mathrm{t}=32.3 \mathrm{~s})$;

- Synchronizing the SSMT 2 with the LV network $(t=57.0 \mathrm{~s})$;

- Synchronizing the SSMT 3 with the LV network $(\mathrm{t}=86.5 \mathrm{~s})$;

- Connecting controllable loads $(\mathrm{t}=100 \mathrm{~s})$;

- Connecting wind generator $(\mathrm{t}=119.7 \mathrm{~s})$;

- Connecting PV $1(\mathrm{t}=130 \mathrm{~s})$;

- Connecting PV $2(\mathrm{t}=140 \mathrm{~s})$;

- Motor loads start-up ( $\mathrm{t}=170 \mathrm{~s}$ and $\mathrm{t}=175 \mathrm{~s})$;

- Changing the control mode of the SSMT $(t=190 \mathrm{~s}, \mathrm{t}=195 \mathrm{~s}$ and $\mathrm{t}=200 \mathrm{~s})$;

- Synchronizing the MG with the MV network $(\mathrm{t}=250.2 \mathrm{~s})$.

During the reintegration phase (synchronization of several controllable MS to the LV grid), a careful verification of the necessary synchronization conditions is required, involving correction in the voltage magnitude and phase angle (frequency) of each VSI to be synchronized with the LV network. The procedure is enabled centrally by the MGCC, but the synchronization conditions are checked locally by each MC. For example, when synchronizing the SSMT 1 with the LV 
network, the procedure is enabled at $\mathrm{t}=25 \mathrm{~s}$; at the same time, a slight frequency variation is made upon the SSMT 1 inverter so that a small phase error can be achieve between the SSMT 1 and MG voltages in order to synchronize them with negligible impact in the network (Fig. 27). The voltage magnitude is also corrected so that it matches the grid voltage, as it can be observed from Fig. 28 at about $\mathrm{t}=30 \mathrm{~s}$. As MG loads are modelled as constant impedances, voltage correction causes a small power increase that can be observed in Fig. 27 and Fig. 28 around $\mathrm{t}=30 \mathrm{~s}$. For synchronizing SSMT 2 and SSMT 3 with the LV grid a similar procedure is followed.
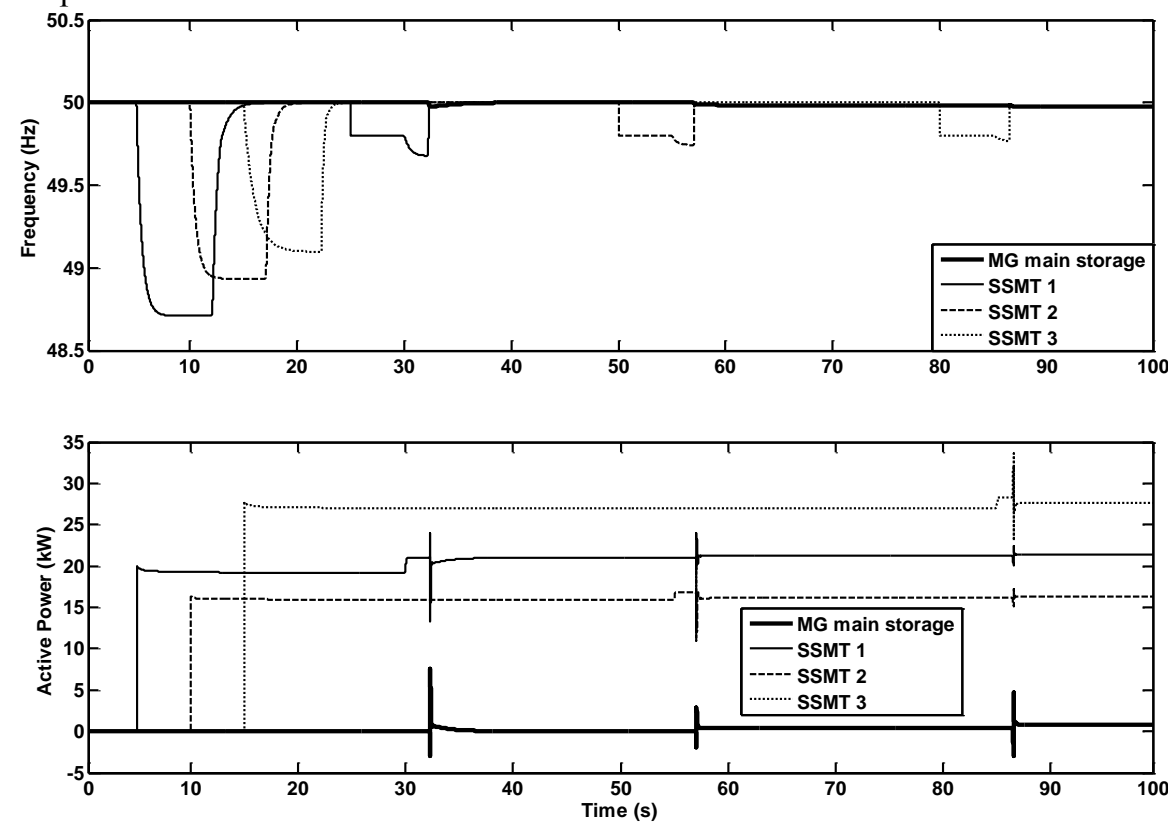

Fig. 27. MS frequencies and active power during the first steps of the black start procedure

The MG long term dynamic behavior was studied using a voltage droop control scheme in all MS with BS capability. Only small adjustments on the idle voltage of inverters are performed in order to minimize the errors in the voltage magnitude before the synchronization. The results obtained demonstrate that the used voltage regulation principle ensures $\mathrm{MG}$ stability and no reactive power oscillations among MS are observed (Fig. 28).

The effect of small motor loads start-up can be observed in Fig. 29 and Fig. 30 around $\mathrm{t}=170 \mathrm{~s}$ and $\mathrm{t}=175 \mathrm{~s}$. Although starting up from the stall position, the effect on the system is not a critical issue because motors are starting up under a multi master operation scheme, as it can be observed in Fig. 29 when analyzing node voltage drop. 
After restoring the full operation of the MG, the control scheme of the SSMT inverters is changed from VSI to PQ control, which is the normal operation mode whenever an external source is used to define MG frequency and voltage. It is possible to observe in Fig. 29 and Fig. 30 that changing the control mode has no significant impact in the MG since the power levels in the MS are maintained (changing the control mode of the several SSMT occurs at $t=190 \mathrm{~s}, \mathrm{t}=195 \mathrm{~s}$ and $\mathrm{t}=200 \mathrm{~s})$.
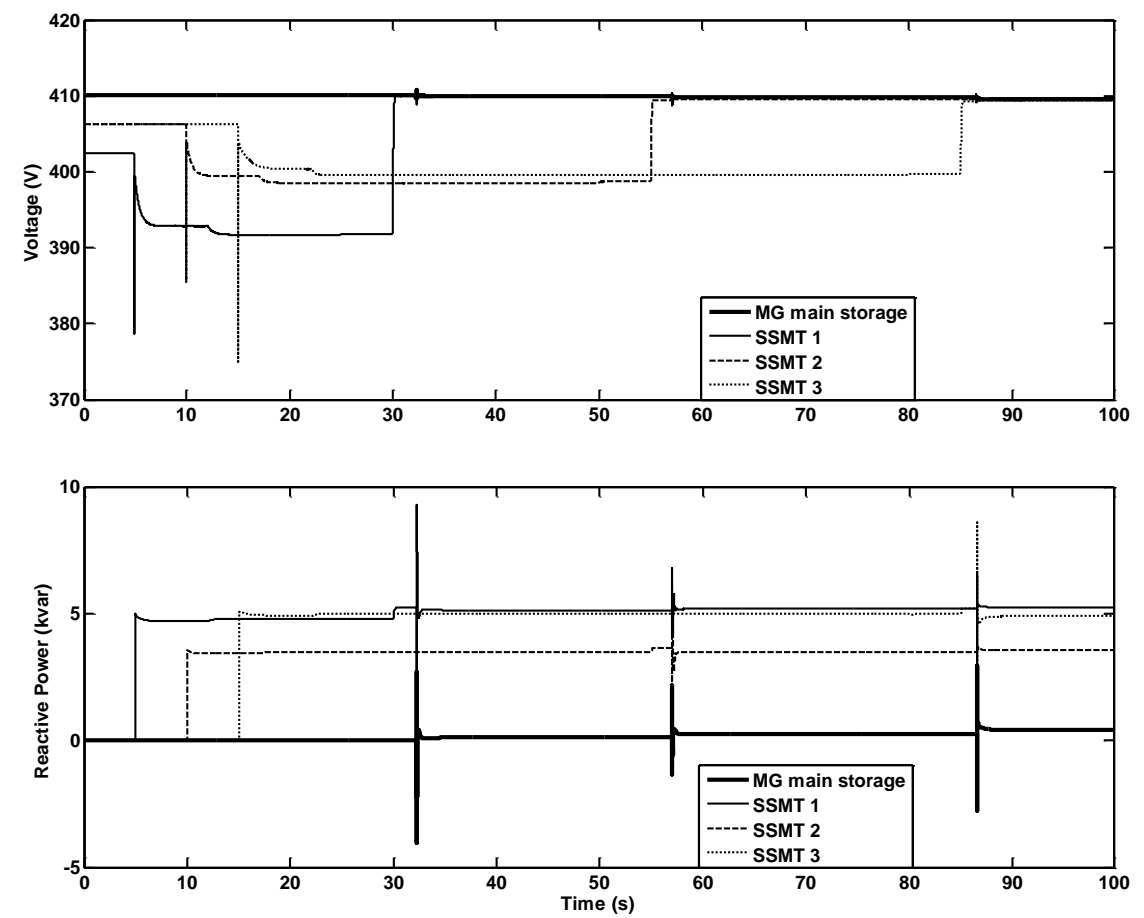

Fig. 28. MS voltages and reactive power during the first steps of the black start procedure

When the MV network becomes available, synchronization with the upstream MV grid needs to be performed. Therefore, the MGCC requires the VSI of the MG main energy storage device to change slightly its frequency and voltage in order to check the synchronization conditions. Fig. 31 shows a detail of the impact of the synchronization procedure in terms of current, active and reactive power flowing in the LV side of the distribution transformer. As the majority of the MG loads is modelled as constant impedances, voltage correction (increase) prior to synchronization provokes an increase in the active power consumption within the islanded MG. After synchronization this power surplus is supplied by the MV network (Fig. 31), since the MG main storage droop imposes a zero power output after synchronization. 

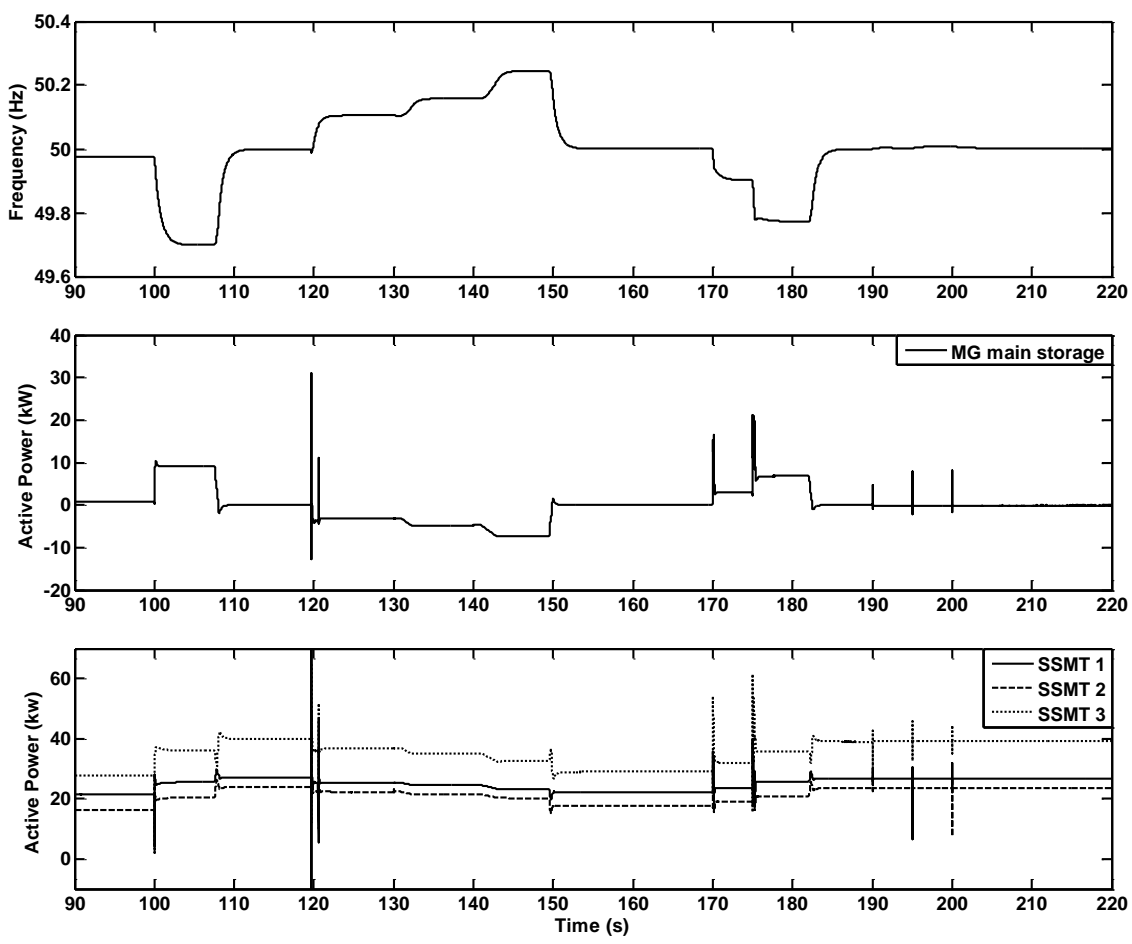

Fig. 29. MG frequency and MS active power output

\subsection{Final Remarks}

Following the increasing penetration of DG in MV networks, the dissemination of different microgeneration technologies such as microturbines, fuel cells, photovoltaic PV panels and micro wind generators, is expected to become one possible approach to face the continuous electricity demand growth. The massive integration of DG units under this approach may cause more problems than those it may solve. Therefore, it is imperative to define new DG integration strategies, through which a system perspective is used in order to exploit the potential benefits DG may provide. Additionally, in the recent times the trend is not to consider DG alone, but in a wider context, which includes the use of energy storage devices and responsive and/or controllable loads. The electrical distribution network of the future will involve more than just massive integration of DG units into the grids. It will require the adoption of more ambitious concepts related to active management of the distribution grids, where loads, storage devices and DG can be used 
together to improve the overall system efficiency, the quality of electricity supply and the overall operating conditions, leading to a fully active distribution network.
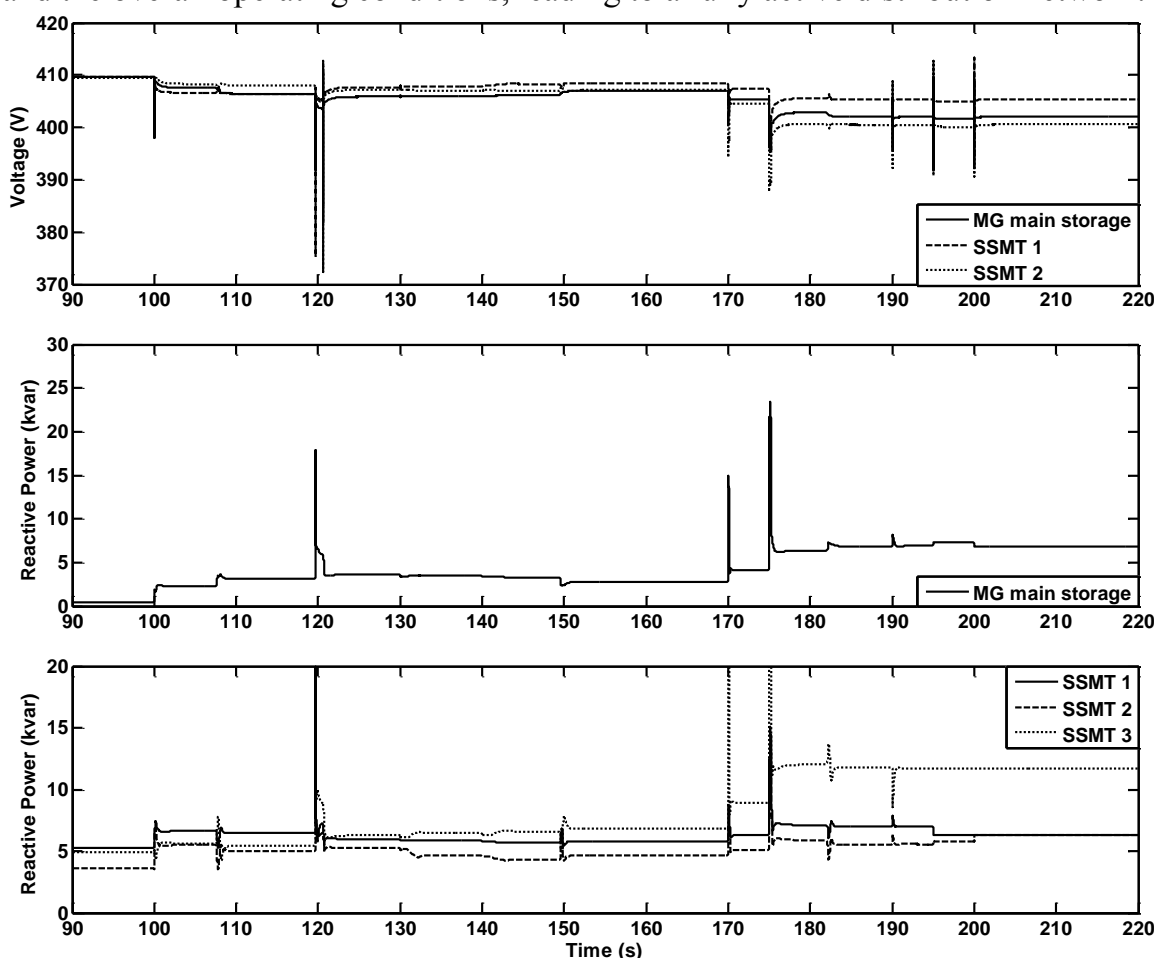

Fig. 30. MS terminal voltages and reactive power output

The cost effective integration of DG into electrical distribution systems depends greatly from the deployment of active management strategies in the planning and operation activities, deeply contrasting with the current connect and forget policies. The intensive use of active management techniques enable the Distribution Network Operators to maximize the use of the existing circuits by taking full advantage of a significant number of control variables, which are not monitorable nor controllable in their current operation and planning philosophies. Under such scenario, it will be possible to implement several functionalities such as active load management, DG active and reactive power dispatch, control of transformer taps, voltage regulation and system reconfiguration in an integrated manner. The key issues for a costly and effectively DG integration in distribution networks requires a massive adoption of new operation and management philosophies aiming to exploit all the available resources. 

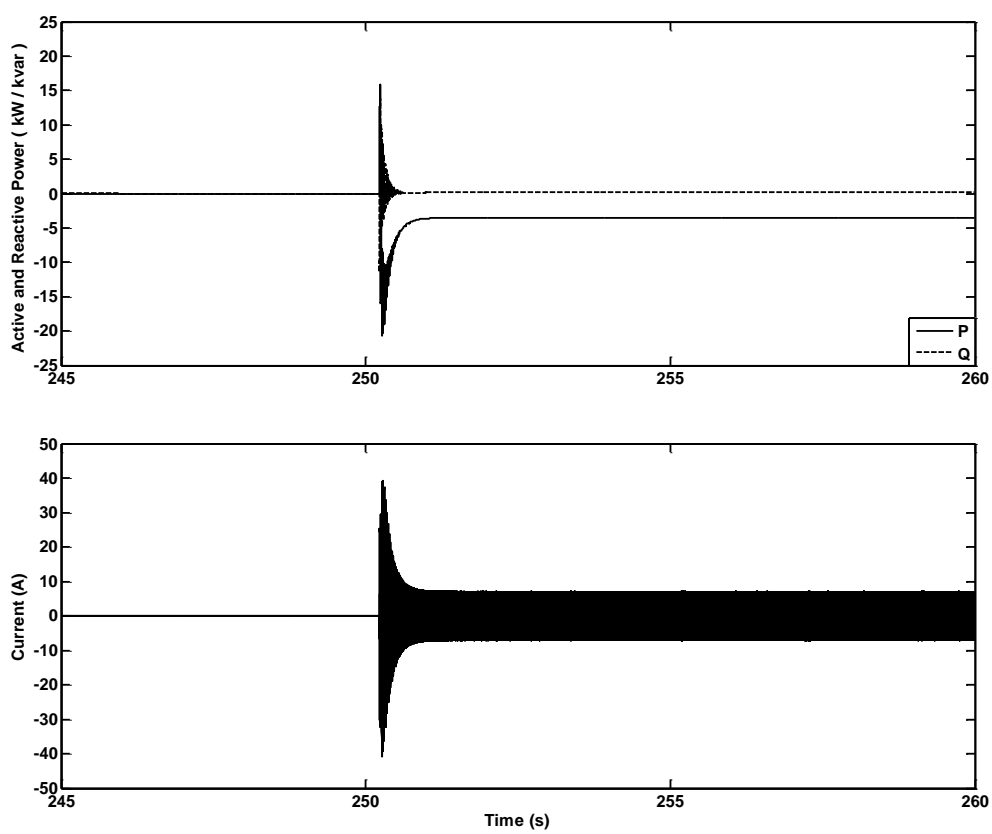

Fig. 31. Synchronization current, active and reactive power in the low voltage side of the distribution transformer

The MG concept consists on the aggregation of loads and MS operating in a single system with appropriate management and control functionalities. Such that both power and heat can be provided to local consumers, allowing in this way a very complete MS integration strategy. In fact, the MG concept leads to the development of an active cell of the distribution network, which has the ability of autonomous operation. Such operation mode that can be exploited in a MG can be considered as a radical change in the current practice followed by distribution network operators, which do not allow islanded operation of parts or sections of the distribution network. 


\section{References}

[1] Lopes JAP, Moreira CL, Madureira AG (2006) Defining control strategies for microgrids islanded operation. IEEE Trans Power Syst 21: 916-924

[2] Moreira CL, Resende FO, Lopes JAP (2007) Using low voltage microgrids for service restoration. IEEE Trans Power Syst 22: 395-403

[3] Katiraei F, Iravani MR, Lehn PW (2005) Microgrid autonomous operation during and subsequent to islanding process. IEEE Trans Power Deliv 20: 248-257.

[4] Katiraei F, Iravani MR (2006) Power management strategies for a microgrid with multiple distributed generation units. IEEE Trans Power Syst 21: 1821-1831

[5] Hatziargyriou N, Asano H, Iravani R, Marnay C (2007), Microgrids. IEEE Power Energy Mag 5: 78-94

[6] Moreira CL (2008) Identification and development of microgrids emergency control procedures. PhD Dissertation, University of Porto

[7] O'Hayre RP (2009) Fuel cell fundamentals. John Wiley \& Sons, New York

[8] Ellis MW, Spakovsky MRV, Nelson DJ (2001), Fuel cell systems: efficient, flexible energy conversion for the 21st century. Proc IEEE 89: 1808-1818

[9] Laughton MA (2002) Fuel cells. Power Eng J (16): 37-47

[10]Rajashekara K (2005) Hybrid fuel cell strategies for clean power generation. IEEE Trans Ind Appl 41: 682-689

[11]Zhu Y, Tomsovic K (2002) Development of models for analyzing the load-following performance of microturbines and fuel cells. Electr Power Syst Res 62: 1-11

[12]Knyazkin V, Soder L, Canizares C (2003) Control challenges of fuel cell-driven distributed generation. Proc IEEE Bologna Power Tech

[13]Li YH, Choi SS, Rajakaruna S. (2005) An analysis of the control and operation of a solid oxide fuel-cell power plant in an isolated system. IEEE Trans Energy Convers 20: 381-387

[14]Wang C, Nehrir MH (2007) A physically based dynamic model for solid oxide fuel cells. IEEE Trans Energy Convers 22: 887-897

[15]Jurado F, Valverde M, Cano A (2004) Effect of a SOFC plant on distribution system stability. J Power Sources 129: 170-179

[16]Guda SR, Wang C, Nehrir MH (2006) Modeling of microturbine power generation systems. Electr Power Compon Syst 34: 1027-1041

[17]Al-Hinai A, Feliachi A (2002) Dynamic model of a microturbine used as a distributed generator. Proc $34^{\text {th }}$ Southeast Symp Syst Theory

[18]Bertani A, Bossi C, Fornari F, Massucco S, Spelta S, Tivegna F (2004), A microturbine generation system for grid connected and islanding operation. Proc IEEE 2004 Power System Conf Expo

[19]Fethi O, Dessaint LA, Al-Haddad K (2004) Modeling and simulation of the electric part of a grid connected microturbine. Proc 2004 IEEE Power Eng Soc Gen Meet

[20]Wang W, Cai R, Zhang N (2003) General characteristics of single shaft microturbine set at variable speed operation and its optimization. Appl Therm Eng 34: 1851-1863

[21]Bose BK (2002) Modern power electronics and AC drives. Prentice Hall, Upper Saddle River - New Jersey

[22]Barakati JD, Kazerani SM, Aplevich M (2009) Maximum power tracking control for a wind turbine system including a matrix converter. IEEE Trans Energy Convers 24: 705-713

[23]Duffie JA, Beckman WA (2006), Solar engineering of thermal processes. John Wiley \& Sons, New York

[24]Esram T, Chapman PL (2007) Comparison of photovoltaic array maximum power point tracking techiques. ," IEEE Trans Energy Convers 22: 439-449.

[25] Hatziargyriou N, Kariniotakis G, Jenkins N, Lopes JAP, Oyarzabal J, Kanellos F, Pivert XL, Jayawarna N, Gil N, Moreira CL, Larrabe Z (2004) Modelling of micro-sources for security studies. Proc 2004 Paris CIGRÉ session 
[26]Green TC, Prodanovic M (2007) Control of inverter-based micro-grids. Electr Power Syst Res 77: 1204-1213

[27]Barsali S, Ceraolo M, Pelacchi P, Poli D (2002) Control techniques of dispersed generators to improve the continuity of electricity supply. Proc IEEE Power Eng Soc Winter Meet

[28]Chandorkar MC, Divan DM, Adapa R (1993) Control of parallel connected inverters in standalone ac supply systems. ," IEEE Trans Ind Appl 29: 136-143

[29]Lasseter R, Piagi P (2000) Providing premium power through distributed resources. Proc $33^{\text {rd }}$ Hawaii Int Conf Syst Sci

[30]Piagi P, Lasseter R (2006) Autonomous control of microgrids. Proc 2006 IEEE Power Eng Soc Gen Meet

[31]Blaabjerg F, Teodorescu R, Liserre M, Timbus AV (2006) Overview of control and grid synchronization for distributed power generation systems. IEEE Trans Ind Appl Electron 53: 1398-1409

[32]Engler A (2001) Control of battery inverters in modular and expandable island grids (in German). PhD Dissertation, University of Kassel

[33]Engler A (2005) Applicability of droops in low voltage grids. Int J Distrib Energy Resour 1: 3-15

[34]Jayawarna N, Jenkins N, Barnes M, Lorentzu M, Papathanassiou S, Hatziargyriou N (2005) Safety analysis of a MicroGrid. Proc Int Conf Future Power System, The Netherlands

[35]Adibi MM, Fink LH (1992) Special considerations in power system restoration. IEEE Trans Power Syst 7: 1419-1427

[36]Ancona JJ (1995) A framework for power system restoration following a major power failure. IEEE Trans Power Syst 10: 1480-1485

[37]Adibi MM, Fink LH (1994) Power system restoration planning. IEEE Trans Power Syst 9: $22-28$

[38]Pham TTH, Béssanger Y, Hadjsaid N, (2009) New challenges in power system restoration with large scale of dispersed generation insertion. IEEE Trans Power Syst 24: 398-406

[39]Adibi MM, Kafka RJ (1991) Power system restoration issues. IEEE Comput Appl Power 4: 19-24 